\title{
Acknowledging the Effect of the Depreciation of Tangible and Intangible Benefits upon the Evaluation of E-Gov Projects
}

\author{
Marcelo Carvalho Fernandes ${ }^{1}$, Antonio Juarez Alencar ${ }^{1 *}$, Eber Assis Schmitz ${ }^{1}$, Monica Ferreira \\ da Silva ${ }^{1}$ and Rigel Procópio Fernandes ${ }^{2}$ \\ ${ }^{1}$ The Tércio Pacitti Institute, Federal University of Rio de Janeiro, Brazil. \\ ${ }^{2}$ Defense Engineering Graduate Program, Military Institute of Engineering, Rio de Janeiro, Brazil. \\ * Corresponding author. Tel.: +55 21 3938-3224; email: antonio.juarez.alencar@gmail.com \\ Manuscript submitted March 26, 2015; accepted June 10, 2015. \\ doi: $10.17706 /$ jsw.10.7.842-868
}

\begin{abstract}
In the complex world we live in government has become one of the most important players in the data processing market. Not only does it collect a considerable amount of data from various sources, but it is also responsible for transforming this data into information and feeding it back into society. In order to reduce running costs and improve efficiency much of the governmental data collection and transformation activity is made by automated and semi-automated means. Therefore, not surprisingly, government is also one of the biggest users of information and communication technology (ICT). All of this has made the analysis of public sector investments in ICT (or e-gov projects) a subject of interest for officials in decision-making positions. This paper presents a method for the evaluation of these investments. The method gives a way to evaluate the tangible and intangible benefits yielded by e-gov projects. Also, it takes into account that the value yielded by both tangibles and intangibles may change during the course of time, and that these changes may affect the value of e-gov projects.
\end{abstract}

Key words: Intangible benefits, valuation of projects, incremental funding of e-gov projects, software engineering.

\section{Introduction}

As the economies of different countries become increasingly interconnected, the world we live in becomes ever more complex [1]. As a result, whatever role a democratic government is required to perform on behalf of its citizens, it is certain to need reliable information upon which to base its decisions and actions [2]. Therefore, governments tend to collect data from various sources, transform this data into information, feed it back into its decision-making processes and make it available to society. Not surprisingly, much of the governmental data collection and transformation activity is made by automated and semi-automated means. This helps to reduce running costs and improve efficiency. As a result, government has become one of the biggest users of information and communication technology (ICT) worldwide [3].

If an ICT investment is made with the view of improving services in the public sector, facilitating the interaction between government and society or improving communication among government bodies, it is often called an e-government initiative, or e-gov initiative for short. In addition, if the investment concerns the execution of just one ICT project, it is most frequently referred to as an e-gov project. An e-gov initiative 
may require the execution of one or several e-gov projects [4]. All of this has made the analysis of e-gov initiatives a subject of interest for officials in decision-making positions.

This paper presents a method to analyse e-gov initiatives. The method is based upon the ideas of Thomas L. Saaty [5] on the use of absolute scales of values to evaluate intangibles and those of Mark Denne and Jane Cleland-Huang [6] on the incremental funding of ICT projects. Moreover, it expands and perfect some of the ideas put forward in [7].

The method presented in this paper addresses several relevant questions regarding e-gov investments that have been overlooked by others (see Section 2 in this respect). As a result, it provides decision makers in the public sector with a tool that allows them to make better investment decisions.

The remainder of this paper is organized as follows. Section 2 presents a review of recent contributions to the evaluation of e-gov initiatives. Section 3 introduces the concepts and methods that are used in the subsequent sections. Section 4 describes the method proposed in this paper with the help of a reasonably complex example. Section 5 provides a more formal and concise description of the method. Section 6 presents the conclusions of this paper.

\section{Related Work}

In recent years many valuable ideas have been put forward to expand the coverage and effectiveness of e-gov evaluation methods. For example, Juell-Skielse and Perjons suggest the adoption of VAMEE, which stands for value aware method for evaluating inclusive e-government initiatives [8]. VAMEE is based on the use of enterprise modelling techniques [9] and value modelling [10].

In VAMEE, enterprise modelling is used to identify the main actors involved in e-gov initiatives and how they are related. Also, enterprise modelling is taken as a basis to elicit how these initiatives are expected to improve the way those actors work. Value modelling is then used to identify the cost of implementing the initiatives and the benefits that they are expected to provide. In VAMEE, cost and benefits are evaluated in monetary units (e.g. American dollars or euros), although the intention is not to obtain accounting precision. Initiatives that yield positive returns are candidates to be implemented.

According to Rausa, Liu and Kip e-gov initiatives frequently involve a large number of heterogeneous stakeholders with different backgrounds, desires and needs [11]. Nevertheless, the value of any e-gov initiative depends on how these needs and desires are incorporated into the projects. The incorporation of needs and desires is especially relevant when the initiative brings considerable innovations to the government services to be automatized. Consistent with this view, they have conceived a value assessment framework that can be used to access business-to-government ICT innovations.

The framework brings together the value perspectives of both the private and public sectors, and the needs and requirements of various stakeholders. Raus, Liu and Kip's framework is comprised of two main parts. The first part takes into account stakeholders' goals and the business areas that require monitoring to build a value matrix. The matrix provides a structure in which different value categories can be compared and assessed. In addition, it helps identifying what ICT dimensions are most worthy of having their value estimated. The second part of the framework provides a sequence of steps that guide stakeholders through the process of deriving assessment criteria, estimating the ICT innovation value and communicating the result of the evaluation process to interested parties.

Berghout and Tan encourage the use of business cases [12] to access the value of IT investment in both the public and private sector [13]. Not only are business cases able to assess multiple dimensions of IT projects, but they can also be used to estimate the projects' impact on users and its implications for corporate strategies. In their work Berghout and Tan claim that business cases can be used to determine the success of IT investments by allowing organizations to make informed decisions about IT projects, monitor 
their progress and evaluate their outcomes upon completion.

Berghout and Tan's business case model is composed of three main parts, i.e. (1) organizational, (2) technological and (3) project constituents. In the first part projects' objectives are established and tangible and intangible benefits are investigated. In the second, technological requirements are drawn and possible suppliers of services and products are identified. In the last part, cost and risk are estimated, and project planning and governance are delineated. The final product of the model is a report in which the findings of the evaluation process are summarized. Berghout and Tan's business case model has been used to assess IT projects in over 30 municipalities in the Netherland with positive results.

Srivastava claims that one of the main difficulties in evaluating e-gov initiatives is to determine the variables of interest, figure whether these variables are of financial or non-financial nature, whether they should be observed at local, state or federal government level, and how the value of e-gov is realized [14]. As a result, Srivastava has developed a framework designed to address these questions. Srivastava's framework takes into account two important dimensions of e-gov initiatives, i.e. the government and the citizen dimensions. The former considers the policy-making proceedings, the effectiveness of the managerial structure and the compliance by organizations and the general public with legislation. The latter is concerned with the social, political, ideological, financial and stewardship aspects of e-gov initiatives.

According to Srivastava the benefits provided by e-gov initiatives can be more effectively analysed by considering the value they create with respect to these two dimensions. Moreover, he argues that the impact on both dimensions stems from improving the efficiency and effectiveness of processes at local, state, and central levels. The final product of Srivastava's framework is a set of guidelines that can be used to better evaluate e-gov initiatives.

Osman et al. revise the existent literature to identify the most critical factors leading to citizen's satisfaction with the automation of government services [15]. Subsequently, these factors are transformed into variables, which are then grouped into a quantitative framework composed of four main dimensions, i.e. cost, benefit; risk and opportunity (or COBRA for short).

Structural equation modelling based on data collected from a case study in Turkey is used to establish relationships among the identified dimensions, associated variables and citizen's satisfaction. According to the authors the results show that COBRA is a reliable approach for evaluating the success of e-government services from the citizens' perspective.

Alencar et al. put forward a method to maximize the intangible benefits provided by IT investments in the public sector [7]. The method recognizes that it is frequently the case that IT investments require the execution of several interconnected projects. Moreover, it acknowledges the dependency relations that may exist among them. In addition, it recognizes that while some projects generate financial returns when they are completed, others do not. As a result, the order in which these projects are run may alter the value they provide. According to the authors, these properties extend to the subprojects that projects are usually divided into, further increasing the value that projects may yield.

Rigel et al. [16] follow some of the ideas outlined by the method devised by Alencar et al. (op cit.). These authors present a proposal to expand that method's ability to cope with different situations, making it suitable to deal with a large number of IT projects simultaneously. In these circumstances Rigel et al. use Kolmogorov's confidence contours [17], [18] to calculate the sample size that complies with a predefined required precision for evaluation estimates. Furthermore, these authors present a restricted but easy to understand graphical convention built upon dependency diagrams [19]. This allows decision makers to establish properties that possible project implementation sequences should have. The graphical convention aims to ensure that the maximum amount of value is delivered by IT investments made at the taxpayer's expense. 
Guclu and Bilgen take the view that it is important to access the ex-ante and ex-post impact on society of e-gov initiatives. Hence, they advocate the use of a multi-dimension model for assessing e-gov initiatives that deal with these two dimensions [20]. The model takes into consideration four dimensions of value creation: (1) agency value - the financial and nonfinancial savings provided by the initiative, (2) user value the benefits provided to the general public, (3) political value - the perception of how well the government carries out its role in society, and (4) social value - how the initiative contributes to enhance the well-being of the general public, the fight for social inclusion, the actions against marginalization, the increase in the sense of belonging and the promotion of hope for a better future, and upward mobility.

According to Guclu and Bilgen their model can be used for the continuous monitoring of e-gov initiatives during their development and implementation phases. Real world data obtained from a portfolio of e-gov projects run by the Turkish government is presented and analysed to demonstrate the usefulness of their model in the real world.

Tsohou et al. defend the idea that e-government initiatives should be primarily evaluated from a citizen's perspective [21]. As a result, they present a reference model for the citizen-centric improvement of e-government services, i.e. a model that delineates how tailor made improvement models should be constructed according to each specific situation.

The reference model suggests that e-gov improvement requires four different steps, i.e. (1) identify target e-services - which identifies highly valuable government services that have undergone automation, (2) construct a citizen's centric evaluation model - identify relevant key performance indicators (KPIs) that are directly connect to citizen's satisfaction with government services (according to the authors such KPIs can be extracted from the existing literature), (3) validate the citizen's centric evaluation model - collect data from different e-gov services and measure the citizen's satisfaction with these services (4) indicate opportunities for improvement - use a mathematical model, such as data envelopment analyses [22], to identify opportunities' for improvement. Tsohou et al. exemplify the use of their reference model using data collected from a sample of the Turkish population.

Tan, Theodorou and Over encourage the adoption of an information technology investment management model, which can be applied to evaluate e-gov initiatives [23]. The model helps identifying what investments are to be made, who should make the investment decisions, how these decisions are to be made, and how they should be monitored and controlled. According to the authors the proposed model provides the necessary means to select, evaluate, monitor and control e-gov investments across their lifecycle.

Tan, Theodorou and Over's investment model establish a structured process that seeks to ensure that investments are well thought-out, support the organization strategic plan, minimize risk, are cost effective and maximize return on investment. The process is divided into three phases: (1) preselect phase stakeholders needs are identified, analysed and documented, (2) select phase - e-gov investments that best support current mission, strategic goals and mandates are identified, and (3) monitoring and control phase - e-gov projects are developed and deployed using disciplined, well-managed and consistent practices.

Neuroni et al. support the idea that the evaluation of e-gov projects needs to take into account political, social and financial aspects, making the assessment of value creation difficult in these projects [24]. As a result, they have developed a framework to assess the value and cost effectiveness of e-government projects that deals with the quantification problem in an appropriated manner. The framework advocates the use of a four-step process. In the first step the goals of the projects under consideration are elicited. The second step is concerned with their financial aspects. In this step the net present value (NPV) is used to estimate the financial value of each project. Flexibility is added to the financial evaluation through the use of real options [25]. 
In a third step, qualitative variables are used to analyse the intangible benefits yielded by the projects. Finally, in the fourth step the findings of the previous steps are brought together, so that different projects can be compared for possible implementation. Neuroni et al. demostrate how their model can be used in the real world by presenting a case study involving the government of Switzerland.

Klischewski and Ukena have devised a method to map value exchange among actors in ICT projects [26]. The method, which can be used to analyse e-gov initiatives, highlights the exchange of both tangible and intangible deliverables. Moreover, it helps identifying stakeholders and the role they play in services to be automatized. The final product of the Klischewski and Ukena's method is a diagram composed of circles, representing actors, and arcs, mapping the exchange of value among actors. The authors claim that the diagram makes it easier to reason on the effect of different implementation choices upon the value to be delivered to each stakeholder by the e-gov initiative. Therefore, it allows for better decision making.

Cao et al., Freeman et al., Peffers and Santos, and Palka et al. present reviews of the existing literature on return on investments made in e-gov projects, and of different approaches to assessing such returns [27]-[30]. However, despite all the effort that has been put into the development of these approaches, they fail to acknowledge that the value of both tangibles and intangibles may change over the course of implementation, and that these changes may affect the value of these projects as a whole.

Moreover, with the exception of Alencar et al. [16] and Rigel et al. [16] these methods fall short with regard to the following points:

a) Recognizing that it is often the case that a single e-gov investment can lead to the creation of several projects, which can be naturally divided into subprojects.

b) Acknowledging that some of these projects and subprojects provide financial returns when they are completed, while others simply lay down the infrastructure required by the other system parts.

c) Taking advantage of the fact that the financial returns yielded by some e-gov projects and subprojects can be used to finance the development of other projects and subprojects.

d) Considering that the order in which projects and subprojects are developed may considerably change the value of the e-gov investment as a whole.

This paper presents a method to evaluate e-gov projects. The proposed method addresses the devaluation of both tangibles and intangibles benefits as well as points a) to d) above. Moreover, the method allows restrictions to be imposed on the implementation of subprojects; so that benefits are always appropriated by the general public (Step 20 of Section 4 discusses this question in more detail). As a result, it provides decision makers with a logical sequence of steps that lead to better investment decisions in respect to e-gov initiatives.

\section{Background}

\subsection{Assets and the Benefits They Provide}

An asset is frequently defined as a valuable resource that can be either possessed or just controlled. For example, a commercial real-state property can be owned and used to develop new ventures. Furthermore, it can be rented out, providing its owners with a steady monthly income. On the other hand, although one may not own a commercial property, he or she may retain the right to use it for business. In many circumstances this right can be sold or leased, proving its controller with income that can be used to acquire and develop other assets [31].

While some of the benefits provided by an asset may be of financial or physical nature, others depend on abstract perceptions of reality. These benefits are called intangibles. For instance, taking a bus is usually cheaper than driving a car. However, many people prefer to drive. Most certainly these people would agree that by and large driving a car is more comfortable, safe and convenient, not to mention the social status 
that some cars may provide to their owners. Note that all these benefits depend on perceptions of reality and, as a result, are intangibles [32].

Governments are non-profitable social and political organizations conceived to increase the well-being of their citizens. Therefore, many of the projects that are run in the public sector aim to provide benefits that are intangibles. For instance, the construction of a well-structured public school facilitates access to quality education. In turn it helps to create better economic opportunities for its students, allows people to hope for a better future and improves confidence in government actions. E-government projects are no exception, as they tend to improve the quality of public services, help to increase the transparency of government investments and expenditure, and make civil servants more accountable for the decisions they make [33].

\subsection{Dealing with Intangibles}

Because intangible benefits do not have a physical or financial embodiment, they tend to be hard to quantify. According to Saaty intangibles are more readily evaluated when they are compared in pairs [34]. The outcome of such a comparison is a number varying from 1 to 9 , indicating how relevant one intangible element is in regard to the other.

On the 1-to-9 scale, also known as Saaty's valuation scale, number one indicates that the two elements have the same relevance. Three is used when one element is moderately more relevant than the other. Five expresses the idea that one element is strongly more relevant than the other. Seven implies an even stronger relevance than five. Finally, nine pinpoints that the relevance of one element in regard to the other is of the highest possible intensity. Intermediate values can be used if necessary.

This leads to the construction of a square matrix in which all the main diagonal elements are $1 \mathrm{~s}$, because one element is always equally relevant to itself. Moreover, the remaining elements of the matrix are either a value taken from the 1-to-9 scale or the reciprocal of one of those values. Such a matrix is often referred to as Saaty's valuation matrix.

For example, take into account a set $\{P S P, P N C, P I T\}$ of intangibles presented in Table 1, which can be used to establish priorities among e-gov projects.

Table 1. Main Evaluation Criteria

\begin{tabular}{|l|}
\hline \multicolumn{1}{|c|}{ Criterion } \\
\hline \hline $\begin{array}{l}\text { Positive support from the general public (PSP) - indicates the positive support that an e-gov project } \\
\text { may receive from the general public }\end{array}$ \\
\hline $\begin{array}{l}\text { Positive news coverage (PNC) - signals the extent of positive news coverage that an e-gov project is } \\
\text { expected to gather as a result of the benefits that the project can provide to different communities }\end{array}$ \\
\hline $\begin{array}{l}\text { Positive effect on tax-collection (PET) - expresses the amount of positive impact that an e-gov project } \\
\text { is expected to have on perfecting and expanding the tax-collection system }\end{array}$ \\
\hline
\end{tabular}

Table 2. Saaty's Valuation Matrix

$\left.\begin{array}{cccccc} & & P S P & P N C & P E T & \\ & & \downarrow & \downarrow & \downarrow & \\ P S P & \rightarrow \\ P N C & \rightarrow \\ P E T & \rightarrow & 1 & 2 & 5 & \\ 1 / 2 & 1 & 3 & \\ 1 / 5 & 1 / 3 & 1\end{array}\right]$

Moreover, suppose that $P N C$ is found to be slightly less relevant than PSP. In addition, let PET to be moderately less relevant than $P N C$ and strongly less relevant than PSP. The Saaty's valuation matrix $V$ introduced in Table 2 captures this information. 
It should be noted that the comparison proposed by Saaty is reciprocal. Therefore, $v_{P N C, P S P}=1 / 2$ the matrix $V$ implies that $v_{P S P, P N C}=2$. In other words, $P N C$ being slightly less relevant than PSP implies that $P S P$ is slightly more relevant than $P N C$. This reciprocal relationship holds for all elements in $V$.

The relevance of the elements that are submitted to the pairwise comparison procedure is given by the corresponding elements of the normalized main eigenvector of $V$. By normalized it is meant that the sum of all the components of the eigenvector is equal to 1, i.e. $100 \%$. Table 3 shows the main eigenvector of the valuation matrix presented in Table 2 .

Table 3. Main Eigenvector

\begin{tabular}{|c|c|c|}
\hline & & $\operatorname{RI}(\%)$ \\
\hline & & $\downarrow$ \\
\hline$P S P$ & $\rightarrow$ & 58.1 \\
\hline$P N C$ & $\rightarrow$ & 30.9 \\
\hline PET & $\rightarrow$ & 11.0 \\
\hline
\end{tabular}

The relevance of the elements being compared in a valuation matrix is usually referred to as their relevance index or $R I$. Therefore, $\operatorname{RI}(P S P)=58.1 \%, \operatorname{RI}(P N C)=30.9 \%$ and $\operatorname{RI}(P E T)=11.0 \%$. Moreover, considering the decision that one is expected to make, PSP is the most relevant element. The second most relevant element is $P N C$, which is followed by PET.

Valuation matrices should not be used for decision making before having their consistency checked. Saaty proposes the use of a consistency ratio $(C R)$ to verify whether a valuation matrix is consistent. For a given $\mathrm{n}$ $n \times n$ valuation matrix that has $\lambda_{\max }$ as its the main eigenvalue, $C R=C I / I$. In these circumstances, $C I$, the consistency index, is the result of $\left(\lambda_{\max }-1\right) /(n-1)$, and $I$, the random index, is drawn from Table 4 according to $n$.

Table 4. The Random Index

\begin{tabular}{|c||c|c|c|c|c|c|c|c|c|}
\hline $\boldsymbol{n}$ & 1 & 2 & 3 & 4 & 5 & 6 & 7 & 8 & 9 \\
\hline $\boldsymbol{I}$ & 0.00 & 0.00 & 0.58 & 0.90 & 1.12 & 1.24 & 1.32 & 1.41 & 1.45 \\
\hline
\end{tabular}

The limit for the consistency ratio varies according to the size of the valuation matrix. According to Saaty or $3 \times 3$ matrices a $C R \geq 0.05$ indicates that the inconsistencies should be fixed. For $4 \times 4$ matrices the limit increases to 0.09 , and for $5 \times 5$ and larger matrices the limit is 0.10 . The $C R$ of the valuation matrix presented in Table 2 is 0.004 . Consequently, it can be safely used for decision making.

Saaty calls this method of pairwise comparison the Analytic Hierarchy Process (AHP). Since it was introduced in the late 1970's [35], the AHP has been successfully used to help with decision making problems in a variety of areas, such as energy planning, medicine, political conflicts and investment analysis. Although the example presented in this section considers just one dimension of intangibles, the AHP provides a structure capable of dealing with a multitude of dimensions, which are organized in a hierarchy. This helps to make the AHP an attractive tool to support the decision making process when dealing with complex problems.

The use of the AHP's hierarchical structuring capabilities to resolve complex decision-making problems is presented in [5] and [36]. A review of the use of the AHP in recent years can be found in [37] and also in 
[38]. An introduction to eigenvectors and eigenvalues is presented in [39].

\subsection{ICT Project Financing}

The idea of dividing ICT projects into subprojects in order to facilitate understanding, planning and maintenance is not new [40]. Nevertheless, as indicated by Denne and Cleland-Huang [41], and endorsed by others [42 - 43], it is frequently the case that ICT projects can be divided into two complementary types of subprojects. While the first generates financial returns as soon as they are completed, the second generates no financial returns whatsoever. Nevertheless, subprojects of the second type are necessary for the development of the infrastructure that is needed by other subprojects and system parts. Denne and Cleland-Huang have named the former minimum marketable feature subprojects (MMFs) and the latter architectural element subprojects (AEs).

Moreover, although some dependency relations may hold true among MMFs and AEs, it is usually the case that the financial returns yielded by a MMF can be used to finance the development of other subprojects. Therefore, the order in which MMFs and AEs are developed tends to affect the financial value of a project, and as a result, the value of portfolios of ICT projects. For example, consider the diagram presented in Fig. 1, in which $M V C_{1}, M V C_{2}, \ldots, M V C_{6}$ are all subprojects of a project named $M V C$. In project management jargon, $M V C$ is said to be the source project of the $M V C_{1}, M V C_{2}, \ldots, M V C_{6}$ subprojects.

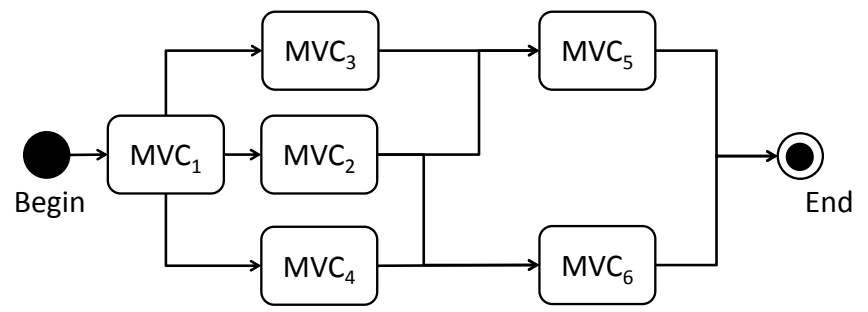

Fig. 1. Dependency diagram of MMFs and AEs.

Note that Begin and End are dummy subprojects, which indicate the beginning and end of the development process. These subprojects take no time to be developed, require no capital investment and yield no final products. An arrow connecting two subprojects, e.g. $M V C_{1} \rightarrow M V C 2$, indicates that the development of the subproject on the left of the arrow (e.g. $M V C_{2}$ ) can only begin when the subproject on the right (e.g. $M V C_{1}$ ) is completed. It should be noted that this kind of dependency relation is transitive. Therefore, because $M V C_{1} \rightarrow M V C_{2}$ and $M V C_{2} \rightarrow M V C_{5}$, necessarily $M V C_{1} \rightarrow M V C_{5}$. In many circumstances transitive relations are not explicitly presented in dependency diagrams so as to keep them simple.

It is important to keep in mind that all the subprojects in Fig. 1 require capital investment to be developed [44]. Table 5 presents the financial inputs and outputs of those subprojects.

Table 5. Cash Flow of MMF and AE Subprojects

\begin{tabular}{|c|c|c|c|c|c|c|c|}
\hline \multirow{2}{*}{$\begin{array}{l}\text { Sub- } \\
\text { Proj. }\end{array}$} & \multirow{2}{*}{ MkSp } & \multicolumn{7}{|c|}{ Period (\$ 1.000K) } \\
\cline { 3 - 8 } & & $\mathbf{1}$ & $\mathbf{2}$ & $\mathbf{3}$ & $\mathbf{4}$ & $\ldots$ & $\mathbf{3 0}$ \\
\hline \hline $\mathrm{MVC}_{1}$ & 1 & -15 & 0 & 0 & 0 & $\ldots$ & 0 \\
\hline $\mathrm{MVC}_{2}$ & 2 & -60 & -20 & 0 & 0 & $\ldots$ & 0 \\
\hline $\mathrm{MVC}_{3}$ & 2 & -70 & -10 & 0 & 0 & $\ldots$ & 0 \\
\hline $\mathrm{MVC}_{4}$ & 1 & -45 & 0 & 0 & 0 & $\ldots$ & 0 \\
\hline $\mathrm{MVC}_{5}$ & 2 & -60 & -30 & 50 & 50 & $\ldots$ & 50 \\
\hline $\mathrm{MVC}_{6}$ & 1 & -45 & 30 & 60 & 90 & $\ldots$ & 90 \\
\hline \hline Total & 9 & \multicolumn{7}{|l}{}
\end{tabular}


In Table 5 the word period stands for an arbitrary length of time, e.g. weeks, months, quarters, etc. Moreover, "\$" is an arbitrary monetary unit, e.g. American dollar, Euro, Japanese yen, etc. The letter "K" is used to indicate a thousand units of $\$$. Negative numbers indicate that a subproject requires financial input, i.e. requires investment. On the other hand, positive numbers indicate that a subproject yields financial returns.

In project management jargon, the length of time between the start of the first project (or subproject) activity and the completion of the last is called project (or subproject) makespan. Often MkSp is used as an abbreviation for makespan [45]. For instance, the $M k S p$ of $M V C_{1}$ is one period. In addition, $M V C_{1}$ requires an investment of $\$ 15 \mathrm{~K}$ (fifteen monetary units) in the first period. It provides no financial returns when it is finished. Hence, subproject $M V C_{1}$ is an AE. Subprojects $M V C_{2}, M V C_{3}$ and $M V C_{4}$ are all also AEs.

Nevertheless, subproject $M V C_{6}$ require an initial investment of $\$ 45 \mathrm{~K}$. This subproject take one period to be completed. However, it yields financial returns from period 2 to 30 . Hence, subprojects $M V C_{6}$ is an MMF. Subproject $M V C_{5}$ follows a similar pattern and is also an MMF.

It might surprise the reader that the flow of financial returns suddenly ends at the thirtieth period. The reasons for this are simple; at this point the final products of those subprojects become obsolete and have to be replaced by an up to date solution. The period of time from the beginning of the development of a set of subprojects until they have to be replaced by an up to date solution is usually referred to as its window of opportunity or $W O$ for short [46]. Therefore, the $W O$ for the subprojects presented in Table 5 is thirty periods.

It is widely accepted that one should not perform arithmetic operations on monetary values without taking an interest rate into consideration [47]. Therefore, in order to compare the financial value of different subprojects, one should use their discounted cash flow. Table 6 presents the sum of the discounted cash flow (or NPV) of each subproject presented in Fig. 1.

Table 6. NPVs of the MVC Subprojects According to the Period when their Development Starts

\begin{tabular}{|c|c|c|c|c|c|c|}
\hline \multirow{2}{*}{$\begin{array}{l}\text { Sub- } \\
\text { Proj. }\end{array}$} & \multicolumn{7}{|c|}{ Period (\$ 1.000K) } \\
\cline { 2 - 7 } & $\mathbf{1}$ & $\mathbf{2}$ & $\mathbf{3}$ & $\mathbf{4}$ & $\ldots$ & $\mathbf{3 0}$ \\
\hline \hline $\mathrm{MVC}_{1}$ & -15 & -15 & -15 & -15 & $\ldots$ & -12 \\
\hline $\mathrm{MVC}_{2}$ & -79 & -79 & -78 & -77 & $\ldots$ & -47 \\
\hline $\mathrm{MVC}_{3}$ & -74 & -74 & -73 & -73 & $\ldots$ & -59 \\
\hline $\mathrm{MVC}_{4}$ & -45 & -44 & -44 & -44 & $\ldots$ & -35 \\
\hline $\mathrm{MVC}_{5}$ & 1,136 & 1,088 & 1,040 & 993 & $\ldots$ & -51 \\
\hline $\mathrm{MVC}_{6}$ & 2,170 & 2,082 & 1,995 & 1,909 & $\ldots$ & -35 \\
\hline
\end{tabular}

Therefore, consider an interest rate of $0.8 \%$ per period, which is used in all the remaining examples presented in this paper. If the development of subproject $M V C_{6}$ starts at period 1 it yields a NPV of

$$
\$ 2,170 \mathrm{~K}=\frac{-\$ 45 \mathrm{~K}}{(1+0.8 \%)^{1}}+\frac{\$ 30 \mathrm{~K}}{(1+0.8 \%)^{2}}+\cdots+\frac{\$ 90 \mathrm{~K}}{(1+0.8 \%)^{30}}
$$

In addition, if the development of $M V C_{6}$ starts in the second period it yields an NPV of $\$ 2,082 \mathrm{~K}$, in the third $\$ 1,995 \mathrm{~K}$, so on and so forth. The monetary figures presented in Table 6 have been rounded to the nearest integer value. The remaining monetary figures presented in this paper follow the same convention.

It should be noted that different implementation sequences yield different $N P V s$. For instance, the implementation sequence $M V C_{1} \rightarrow M V C_{4} \rightarrow M V C_{2} \rightarrow M V C_{6} \rightarrow M V C_{3} \rightarrow M V C_{5}$ has a $M k S p$ of 9 periods and yields an $N P V$ of $\$ 2,465 \mathrm{~K}$. To calculate this figure it is assumed that just one development team is available to work on the project and that the development of the first subproject starts in the first period. 
Moreover, once the development of the different subprojects starts it cannot be interrupted or delayed. This assumption is held to be true throughout this paper. Nevertheless, although the same restrictions apply to the implementation sequence $M V C_{1} \rightarrow M V C_{3} \rightarrow M V C_{4} \rightarrow M V C_{2} \rightarrow M V C_{5} \rightarrow M V C_{6}$, it yields an NPV of $\$ 2,259 \mathrm{~K}$.

\subsection{Appreciation and Depreciation of Intangibles}

In many circumstances, the time gap between obtaining AHP results and making a decision is short. Therefore, it is reasonable to assume that the value of the intangibles under consideration remains unaltered over this period [37]. Unfortunately, this may not be true for decisions concerning the implementation of e-gov initiatives, which may take anything from several months to several years to be completed [48]. When analyzing the implementation of such initiatives one may have to consider that the value of intangible benefits may appreciate, depreciate or remain the same during the initiative makespan. It is important to keep in mind that these changes may affect the total value of e-gov projects and subprojects alike [49].

Moreover, it is usually the case that some e-gov projects provide financial returns when implemented, either by increasing tax revenue or reducing running costs, and sometimes both. As a result, the financial returns provided by some e-gov projects can be used to finance the development of other projects. This reduces not only the need for capital investment, but also the risk that every e-gov project is naturally exposed to [50].

The same line of reasoning can be applied to subprojects, i.e. the financial returns provided by some e-gov subprojects can be used to finance the development of other projects and subprojects. However, the division of projects into subprojects facilitates the identification of smaller system parts that provide financial return when they are completed. This reduces even further the need for capital investment and the risk exposure of e-gov initiatives. See [51] in this respect.

In the next sections the AHP and project financing principles are combined to produce a method to analyse e-gov initiatives. In contrast to other approaches, this method takes into consideration that changes in both the tangible and intangible aspects of projects may affect the value of the whole e-gov initiative.

\section{Example}

Setting an example is one of the most effective way of influencing others [52]. Therefore, the method presented in this paper is introduced gradually with the help of a real-world inspired example ${ }^{1}$. At this point readers may wish to refer to the subsequent Section 5, which presents a precis of what is introduced in this section.

\section{Step 1: E-gov project selection}

Imagine a large city somewhere in the world. For the purpose of this paper this city is called Sobek. As in many other expanding cities, the number of motor vehicles on Sobek's streets has been increasing at an alarming rate. Traffic jams that were unheard of until a few years ago are now becoming a fact of everyday life. Although some structural and signaling improvements have been made at critical points, the results have fallen short of expectations and the problem persists.

Sobek's mayor is eager to deal with the situation before it gets out of control. As a result, the mayor has instructed Sobek's traffic control and management office (TCMO) to study the problem and present possible solutions. The TCMO is the municipal agency responsible for maintaining a steady flow of traffic all over the city.

1The projects that inspired this example are under consideration by the mayor's office of a major South America city. A fictitious city name has been used throughout this example to preserve the anonymity of its mayor's office and traffic control management office. 
A recent survey conducted by the TCMO has targeted drivers in Sobek's most congested traffic areas. Surprisingly the survey revealed that a considerable amount of traffic is not caused by drivers who want to get to these areas, but by drivers who have already arrived there and are looking for a place to park.

Therefore, one of the suggestions presented by the TCMO is the development of an e-gov system that allows drivers to book public and private parking space in the congested areas in advance. As a result, the old mechanical parking meters used by the TCMO will have to be replaced by new remotely controlled digital parking meters. In addition, a dedicated website will have to be built, together with multi-platform mobile applications. Furthermore, legislation will have to be passed requiring private car parks in selected areas to provide an equivalent service using the system's website.

The survey carried out by the TCMO also revealed that Sobek's drivers are not keen on abiding by the law when it comes to traffic legislation, especially when traffic is heavy. In these circumstances, they tend to ignore legislation, using lanes that should only be used by buses and taxis during restricted hours. In addition, when traffic allows it, drivers tend to go over the established speed limit, causing accidents that could have been easily avoided if they were less impatient. Hence, a system to aid the enforcement of traffic legislation has been added to the suggestions compiled by the TCMO.

This particular system uses speed limit radars, high definition cameras and license place recognition software to control the use of dedicated taxi and bus lanes and also to enforce the speed limit at critical points. Fines are issued electronically, which include photographic evidence of the infraction. Considering that vehicle owners are notified immediately, it is expected that the system will reduce the number of traffic related accidents considerably.

As real-time data on the traffic situation is of paramount importance for decision making, a data gathering system has been added to the TCMO list of suggestions. The system requires the development of a specialized social network that allows drivers to exchange information about the traffic situation. Moreover, a series of wide-angle cameras will have to be installed at critical points, allowing the TCMO to analyze the flow of vehicles and detect potential bottlenecks. All of this will enable the TCMO to indicate the best route between different points of interest in Sobek's urban area and act upon congestion points before the situation gets worse.

Table 7. Sobek's Portfolio of E-Gov Projects

\begin{tabular}{|c|l|}
\hline Id & Project Description \\
\hline \hline WPS & $\begin{array}{l}\text { Wide-area parking-space system - using a bidirectional wireless sensor array and digital parking meters the } \\
\text { system enables drivers to book parking space in designated areas in advance. This way they know where to } \\
\text { park their cars before they get there. If no free parking space can be found, a proportion of drivers will feel } \\
\text { compelled to use other means of transportation }\end{array}$ \\
\hline MVC & $\begin{array}{l}\text { Motor-vehicle control system - uses an array of radars, high definition cameras and license plate recognition } \\
\text { software to monitor the use of dedicated taxi and bus lanes and to enforce vehicle's speed limit. Fines are } \\
\text { issued electronically to vehicles that are caught breaking the law and received by the vehicles' owners } \\
\text { immediately }\end{array}$ \\
\hline TFM & $\begin{array}{l}\text { Traffic flow monitoring system - collects, analyses and broadcasts information about traffic conditions to the } \\
\text { general public and also to the city traffic management office. The system uses a of combination wide-angle } \\
\text { cameras and a dedicated social network to collect and broadcast information about the traffic situation citywide }\end{array}$ \\
\hline TLC & $\begin{array}{l}\text { Traffic light control system - controls all traffic lights in Sobek's urban area. As a result, the duration of the green, } \\
\text { yellow and red lights can be dynamically adjusted according to demand. The system uses a wi-fi control device } \\
\text { that can be added to existing traffic lights. This wi-fi device allows traffic lights to be controlled remotely }\end{array}$ \\
\hline
\end{tabular}

Finally, the TCMO pointed out that traffic could be considerably improved if traffic lights were remotely controlled. The gap between the green, yellow and red lights could be dynamically adjusted according to demand, so as to optimize the flow of motor vehicles. In this case, the data for optimization comes from sensors installed in the traffic lights. A computer system would have to be developed to support this idea. Table 7 presents a summary of the e-gov projects proposed by the TCMO. 


\section{Step 2: WO and MkSP elicitation}

As in many other democratic cities, in Sobek the mayor's term in office is limited. According to current legislation the mayor has to face an election at regular intervals. As election results are frequently hard to predict well in advance, the fate of the projects in Table 7 that are not implemented during the current administration is highly uncertain. One can never tell whether a new mayor is going to support or reject unfinished projects started by the previous administration. As a result, the TCMO and the mayor's office have agreed on an eighteen-period makespan and a thirty-period window of opportunity for the e-gov projects in Table 7.

\section{Step 3: Identify the evaluation criteria}

Furthermore, financial restrictions prevent projects from being run in parallel. Therefore, only a subset of the projects in Table 7 is likely to be implemented. As a result, it is desirable that those projects deliver the maximum amount of benefit possible to Sobek's citizens. Unfortunately choices will have to be made. In line with the view of the mayor's office, the TCMO has adopted the criteria described in Table 1 to prioritize the execution of the projects in Table 7.

\section{Step 4: Prioritize the evaluation criteria}

The valuation matrix introduced in Table 2 captures the opinion of the mayor's office on the relative importance of each criterion introduced in Table I. Such an opinion is based on Sobek's current political, economic and social landscape, which is expected to remain unchanged during the portfolio's makespan. According to the information displayed in Table 3, support from the general public (PSP) is the most relevant criterion. The positive news coverage (PNC) is the second most relevant criterion and the positive effect on tax collection (PET) is the least.

\section{Step 5: Select the absolute scale}

Distinct projects may perform quite differently when subjected to the same set of criteria. For example, all the projects in Sobek's portfolio are highly innovative and bring considerable benefits to different echelons of Sobek's society. See Table 7 in this respect. Therefore, in general, they are bound to gather extensive support from the public and the media.

However, the WPS project may be an exception to this line of reasoning, as it is seen by Sobek's ordinary citizens to be mostly beneficial to the upper echelons of society. Therefore, the WPS project is unlikely to be highly regarded by the general public.

Nevertheless, some of the e-gov projects allow new revenue to be collected or make the current collection system more efficient. This extra revenue can be used to benefit Sobek's citizens in a variety of areas such as education, health, emergency services and communication. For instance, the MVC project is expect to increase tax collection by fining drivers that do not abide by the law. Moreover, the WPS facilitates revenue collection and makes it less costly, as the new parking meters are cheaper to install and maintain.

It should be noted that project performance may vary according to the period in which it makes its deliverables available for use. This holds true even if project performance involves intangibles. For instance, it is a well-known fact that the media is likely to give considerably more attention to the first person or organization to achieve a goal of interest, than to the second or third one [53]. For example, Neil Armstrong, the first man to walk on the moon, yields almost 10 million hits on Google. Edwin Eugene Aldrin, the second man on the moon, yield about $20 \%$ of those hits and Pete Conrad, the third man on the moon, just $10 \%$.

Some cities around the word have already stated that they are considering running projects that are similar to the projects proposed by the TCMO. The mere announcement of their intentions is enough to hinder the exclusive news coverage that Sobek's projects could have enjoyed otherwise. In these circumstances the media feels compelled to broadcast news involving several cities instead of just one. Moreover, if any of those cities finishes one or several of these projects first, the news coverage for the 
corresponding projects run by Sobek is likely to be considerably reduced.

In order to properly consider the performance of the projects in Sobek's portfolio under such conditions, the TCMO has decided to follow Saaty's ideas on the use of the AHP to construct absolute scales of values [54]. As a result, the following scale has been selected to rank the projects under analysis using the set of criteria presented in Table 1: Extreme, High, Moderate, Small, and Insignificant (Insig.).

Table 8. The Relative Relevance of the Scale Elements

\begin{tabular}{|c|c|c|c|c|c|c|c|}
\hline & & Extreme & High & Moderate & Small & Insig. & RI(\%) \\
\hline & & $\downarrow$ & $\downarrow$ & $\downarrow$ & $\downarrow$ & $\downarrow$ & $\downarrow$ \\
\hline Extreme & $\rightarrow$ & 1 & 2 & 4 & 8 & 9 & 48.8 \\
\hline High & $\rightarrow$ & $1 / 2$ & 1 & 2 & 4 & 8 & 27.4 \\
\hline Moderate & $\rightarrow$ & $1 / 4$ & $1 / 2$ & 1 & 2 & 3 & 12.8 \\
\hline Small & & $1 / 8$ & $1 / 4$ & $1 / 2$ & 1 & 2 & 6.9 \\
\hline Insig. & $\rightarrow$ & $1 / 9$ & $1 / 8$ & $1 / 3$ & $1 / 2$ & 1 & 4.1 \\
\hline
\end{tabular}

\section{Step 6: Work out the RI of each element of the scale}

In order to make the relevance relationships that hold true among the elements of the scale clear, they have been subjected to the Saaty valuation matrix. Table 8 shows this matrix. It should be noted that $R I($ Extreme $)=48.8 \%, R I($ High $)=27.4 \%, \ldots, R I$ (Insig. $)=4.1 \%$. Also, the CR of the valuation matrix is smaller than 0.1 , indicating that the scale is consistent and that these RIs can be safely used for decision making.

\section{Step 7: Evaluate the current performance of the e-gov projects}

Table 9 shows the performance of the projects in Sobek's portfolio, considering the criteria introduced in

Table 1 and the ranks presented in Table 8. This performance appraisal has been done by the TCMO in conjunction with Sobek's mayor office. Also, the appraisal assumes that the deliverables of those projects are made available for use at the present time.

Table 9. Project Performance

\begin{tabular}{|c|l|l|l|}
\hline \multirow{2}{*}{$\begin{array}{c}\text { E-gov } \\
\text { Project }\end{array}$} & \multicolumn{3}{|c|}{ Criterion } \\
\cline { 2 - 4 } & \multicolumn{1}{|c|}{ PSP } & \multicolumn{1}{|c|}{ PNC } & \multicolumn{1}{|c|}{ PET } \\
\hline \hline$W P S$ & Moderate & High & High \\
\hline$M V C$ & Extreme & Extreme & High \\
\hline$T F M$ & Extreme & Extreme & Insig \\
\hline$T L C$ & Moderate & High & Insig \\
\hline
\end{tabular}

\section{Step 8: Calculate the current WRI of each e-gov project}

It should be noted that the WPS project ranks Moderate in the general-public support criterion, and High in the news coverage and tax-collection criteria. The other projects in Sobek's portfolio also tend to follow the same pattern, i.e. they perform better in some criteria than in others. A balanced view of the performance of the WPS and the other projects in respect to the criteria introduced in Table 1 can be more easily obtained with a weighted relevance index, or WRI. For a given project $P_{\alpha}$,

$$
W R I\left(P_{\alpha}\right)=\sum_{i=1}^{n} R I\left(C_{i}\right) \times R I_{C_{i}}\left(P_{\propto}\right)
$$

where $\operatorname{RI}\left(C_{i}\right)$ is the relevance index of criterion $C_{i}$, and $R I_{C i}\left(\mathrm{P}_{\alpha}\right)$ is the relevance of $\mathrm{P}_{\alpha}$ when subjected to criterion $C_{i}$. For, example, let $P_{\alpha}$ be the WPS project, and $C_{i} \in\{P S P, P N C, P E T\}$; see Table 1 in this respect. According to Table 3, RI(PSP), RI(PNC) and RI(PET) are respectively 58.1\%, 30.9\% and $11.0 \%$. Moreover, 
according to Table 8 and 9, $R I_{P S P}(W P S)=R I($ Moderate $)=12.8 \%$ and $R I_{P N C}(W P S)=R I_{P E T}(W P S)=R I(H i g h)=$ $27.4 \%$. Therefore, $W R I(W P S)=18.9 \%$.

Table 10 shows the weighted relevance index of each project in Sobek's portfolio together with the corresponding calculation details. As the WRI presented in Table 10 assumes that the deliverables of those projects are made available for use at the current time, it is referred to as their current WRI.

Table 10. Combined Performance of the Projects in Sobek's Portfolio

\begin{tabular}{|c|c|}
\hline Project & Current WRI (\%) \\
\hline \hline$W P S$ & $\mathbf{5 8 . 1} \times \mathbf{1 2 . 8}+\mathbf{3 0 . 9} \times \mathbf{2 7 . 4}+\mathbf{1 1 . 0} \times \mathbf{2 7 . 4}=\mathbf{1 8 . 9}$ \\
\hline$M V C$ & $\mathbf{5 8 . 1} \times \mathbf{4 8 . 8}+\mathbf{3 0 . 9} \times \mathbf{4 8 . 8}+\mathbf{1 1 . 0} \times \mathbf{2 7 . 4}=\mathbf{4 6 . 4}$ \\
\hline$T F M$ & $\mathbf{5 8 . 1} \times \mathbf{4 8 . 8}+\mathbf{3 0 . 9} \times \mathbf{4 8 . 8}+\mathbf{1 1 . 0} \times \mathbf{4 . 1}=\mathbf{2 5 . 2}$ \\
\hline$T L C$ & $\mathbf{5 8 . 1} \times \mathbf{1 2 . 8}+\mathbf{3 0 . 9} \times \mathbf{2 7 . 4}+\mathbf{1 1 . 0} \times \mathbf{4 . 1}=\mathbf{1 6 . 7}$ \\
\hline
\end{tabular}

Therefore, according to the TCMO, at present the $M V C$ is the most relevant project in Sobek's portfolio of e-gov projects, followed respectively by the TFM, WPS and TLC projects.

\section{Step 9: Evaluate the future performance of the projects}

Table 11 presents the performance of the projects in Sobek's portfolio assuming that their deliverables are made available at the end of the allowed makespan. It should be noted that the news coverage of the projects in Sobek's portfolio is considerably affected by the passage of time. By the end of the allowed makespan it is very likely that other cities will have implemented projects that are similar to those in Sobek's portfolio. As a result, the positive news coverage of these projects and the public support for them are certain to be reduced. The figures presented in Table 11 indicate the estimated effect of the passage of time on the WRI of the projects in Sobek's portfolio.

Table 11. Project Performance Assuming that Deliverables are Made Available at the End of the Allowed Makespan

\begin{tabular}{|c|l|c|c|}
\hline \multirow{2}{*}{$\begin{array}{c}\text { E-gov } \\
\text { Project }\end{array}$} & \multicolumn{3}{|c|}{ Criterion } \\
\cline { 2 - 4 } & PSP & PNC & PET \\
\hline \hline$W P S$ & Small & Small & High \\
\hline$M V C$ & Moderate & Small & High \\
\hline$T F M$ & High & Small & Insig \\
\hline$T L C$ & Small & Small & Insig \\
\hline
\end{tabular}

\section{Step 10: Calculate the future WRI of each project}

Table 12 presents the WRI of the projects in Sobek's portfolio assuming that their deliverables are made available at the end of the allowed makespan. As a result the weighted relative index presented in Table 12 is referred to as their future WRI. It should be noted that the future WRI of the projects in Sobek's portfolio is considerably affected by the passage of time. In this respect the figures presented in Table 12 may be compared with those shown in Table 10.

Table 12. Combined Performance of the Projects in Sobek's Portfolio at the End of the Allowed Makespan

\begin{tabular}{|c|cr|}
\hline Project & Future WRI (\%) \\
\hline \hline$W P S$ & $58.1 \times 6.9+30.9 \times 6.9+11.0 \times 27.4=$ & 9.1 \\
\hline$M V C$ & $58.1 \times 12.8+30.9 \times 6.9+11.0 \times 27.4=12.6$ \\
\hline$T F M$ & $58.1 \times 27.4+30.9 \times 6.9+11.0 \times 4.1=18.5$ \\
\hline$T L C$ & $58.1 \times 6.9+30.9 \times 6.9+11.0 \times 4.1=6.6$ \\
\hline
\end{tabular}

\section{Step 11: Relate the present and future performance}

Table 13 shows the estimated effect of the passage of time on the WRI of the projects in Sobek's 
portfolio.

Table 13. The Effect of Time on the WRI of the Projects in Sobek's Portfolio

\begin{tabular}{|c|c|c|c|c|c|r|r|r|r|c|}
\hline \multirow{2}{*}{ Project } & \multicolumn{10}{|c|}{ Period } \\
\cline { 2 - 11 } & $\mathbf{1}$ & $\mathbf{2}$ & $\mathbf{3}$ & $\mathbf{4}$ & $\ldots$ & MkSp-1 & MkSp & MkSp+1 & $\ldots$ & W0 \\
\hline \hline$W P S$ & $18.9 \%$ & $18.3 \%$ & $17,7 \%$ & $17.1 \%$ & $\ldots$ & $9.7 \%$ & $9.1 \%$ & $9.1 \%$ & $\ldots$ & $9.1 \%$ \\
\hline$M V C$ & $46.4 \%$ & $44.3 \%$ & $42.2 \%$ & $40.1 \%$ & $\ldots$ & $14.7 \%$ & $12.6 \%$ & $12.6 \%$ & $\ldots$ & $12.6 \%$ \\
\hline$T F M$ & $43.9 \%$ & $42.3 \%$ & $40.7 \%$ & $39.1 \%$ & $\ldots$ & $20.1 \%$ & $18.5 \%$ & $18.5 \%$ & $\ldots$ & $18.5 \%$ \\
\hline$T L C$ & $16.4 \%$ & $15.8 \%$ & $15.2 \%$ & $14.5 \%$ & $\ldots$ & $7.2 \%$ & $6.6 \%$ & $6.6 \%$ & $\ldots$ & $6.6 \%$ \\
\hline
\end{tabular}

Table 14. Subprojects Comprising the Wide-Area Parking-Space Booking System

\begin{tabular}{|c|l|}
\hline Id & \multicolumn{1}{c|}{ Description } \\
\hline \hline$W P S_{1}$ & $\begin{array}{l}\text { Choose and test the equipment to be used in the project, i.e. the new digital parking meters and the network } \\
\text { access points that allow them to be remotely controlled }\end{array}$ \\
\hline$W P S_{2}$ & $\begin{array}{l}\text { Build the wide-area parking space reservation system together with the corresponding parking meter control } \\
\text { system. This includes an exclusive website and multi-platform mobile phone applications }\end{array}$ \\
\hline$W P S_{3}$ & $\begin{array}{l}\text { Buy enough digital parking meters and network access points to replace the existing mechanical } \\
\text { parking meters in designated areas }\end{array}$ \\
\hline$W P S_{4}$ & Substitute the old equipment with the new one integrating them into the system \\
\hline$W P S_{5}$ & Make the parking meter reservation and control system available for use by the general public \\
\hline$W P S_{6}$ & Bring privately owned parking spaces in the designated areas into the system \\
\hline$W P S_{7}$ & Allow advertising to take place in the system's website and mobile phone applications \\
\hline
\end{tabular}

Table 15. Subprojects Comprising the Motor-Vehicle Control System

\begin{tabular}{|c|l|}
\hline Id & \multicolumn{1}{c|}{ Description } \\
\hline \hline$M V C_{1}$ & $\begin{array}{l}\text { Select the radar, high definition camera and license plate recognition software to be used in the } \\
\text { parking-space booking system }\end{array}$ \\
\hline$M V C_{2}$ & $\begin{array}{l}\text { Develop the motor-vehicle control system, integrating it into the existing motor-vehicle fining } \\
\text { information system }\end{array}$ \\
\hline$M V C_{3}$ & Acquire enough radars cover the streets to be monitored and deploy them \\
\hline$M V C_{4}$ & $\begin{array}{l}\text { Acquire enough high definition cameras to cover the dedicated taxi and bus lanes to be monitored and deploy } \\
\text { them }\end{array}$ \\
\hline$M V C_{5}$ & $\begin{array}{l}\text { Integrate the radars and cameras into the speed control sub-system, deploy the sub-system and } \\
\text { start fining the vehicles that do not abide the law }\end{array}$ \\
\hline$M V C_{6}$ & $\begin{array}{l}\text { Integrate the cameras into the taxi and bus lane monitoring sub-system, deploy the sub-system and start } \\
\text { fining vehicles that do not comply with the dedicated lane regulation }\end{array}$ \\
\hline
\end{tabular}

Table 16. Subprojects Comprising the Traffic Flow Monitoring System

\begin{tabular}{|c|l|}
\hline Id & \multicolumn{1}{|c|}{ Description } \\
\hline \hline$T F M_{1}$ & Develop the dedicated social network \\
\hline$T F M_{2}$ & Deploy the dedicated social network \\
\hline$T F M_{3}$ & Select the wide-angle cameras and develop the traffic monitoring system \\
\hline$T F M_{4}$ & Acquire sufficient cameras, deploy then all over the city and integrate them into the system \\
\hline$T F M_{5}$ & Integrate the social network into the system \\
\hline$T F M_{6}$ & Deploy the traffic flow monitoring system \\
\hline
\end{tabular}

Table 17. Subprojects Comprising the Traffic Flow Monitoring System

\begin{tabular}{|l|l|}
\hline Id & \multicolumn{1}{c|}{ Description } \\
\hline \hline$T L C_{1}$ & Select the wi-fi control device and sensor to be used in the system \\
\hline$T L C_{2}$ & Develop the control system \\
\hline$T L C_{3}$ & $\begin{array}{l}\text { Acquire enough wi-fi control devices and sensors to cover all traffic lights in Sobek's urban area. } \\
\text { Deploy these devices and sensors }\end{array}$ \\
\hline$T L C_{4}$ & Integrate the wi-fi control devices and sensors into the system \\
\hline$T L C_{5}$ & Deploy the traffic light control system \\
\hline
\end{tabular}


Different kinds of functions can be used to estimate the WRIs over the course of time [55-56]. Nevertheless, as the changes in the WRI are believed to happen steadily over time, a straight line has been used in these circumstances. Observe that the WRI of the projects in Sobek's portfolio decreases until the end of the allowed makespan. During this period it is likely that Sobek will be sharing news coverage with an increasing number of other cities.

By the end of the allowed makespan the WRI reaches its lowest value as some of the other cities will have surely completed projects that are similar to those in Sobek's portfolio. After that the WRI remains constant, indicating that the WRI retains a residual value, which lasts until the end of the window of opportunity. Residual values are a common phenomenon regarding intangibles; see [57] for a discussion about this subject.

In formal terms, values presented in Table 13 may be calculated with the help of the following equation

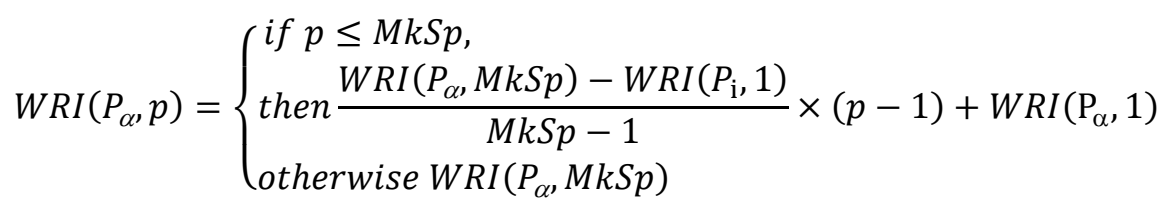

where $\operatorname{WRI}\left(P_{\alpha}, p\right)$ is the $W R I$ of a project $P_{\alpha}$ in period $p$. Therefore, WRI(WPS,3) is given by

$$
\frac{9.1-18.9}{18-1} \times(3-1)+18.9=17.7 .
$$

\section{Step 12: Partition the projects}

It is a well-established principle of ICT project management that dividing projects into subprojects, while keeping a high degree of separation of concerns among them, helps with planning, estimation, development and maintenance [40]. Therefore, the projects in Sobek's portfolio have been divided into a number of subprojects. Tables 14, 15, 16 and 17 introduce these subprojects.

\section{Step 13: Evaluate the current performance of the subprojects}

E-gov subprojects tend to behave in the same way e-gov projects do when it comes to project performance. For instance, the performance of subprojects may vary when subjected to different criteria and their performance in those criteria may vary with the passage of time. Table 18 presents (with an unshaded background) the WRI of subprojects comprising the MVC project. The information presented in Table 18 takes into account that the deliverables of those subprojects are made available for use at the beginning of the allowed portfolio makespan.

\begin{tabular}{|c|c|c|c|c|c|}
\hline \multirow{2}{*}{ Sub-project } & \multicolumn{3}{|c|}{ Criterion } & \multirow{2}{*}{$\begin{array}{c}\text { Current } \\
\text { WRI } \\
(\%)\end{array}$} & \multirow{2}{*}{$\begin{array}{c}\text { Current } \\
\text { AWRI } \\
\text { (\%) }\end{array}$} \\
\hline & PS & MC & EI & & \\
\hline 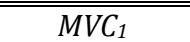 & Small & "High & Insig. & 12.9 & 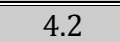 \\
\hline$M V C_{2}$ & Moderate & Moderate & Insig. & 11.9 & 3.8 \\
\hline$M V C_{3}$ & Small & High & Insig. & 12.9 & 4.2 \\
\hline$M V C_{4}$ & Small & High & Insig. & 12.9 & 4.2 \\
\hline$M V C_{5}$ & Extreme & Extreme & High & 46.4 & 15.0 \\
\hline$M V C_{6}$ & Extreme & Extreme & High & 46.4 & 15.0 \\
\hline & & & Total & 143.5 & 46.4 \\
\hline
\end{tabular}

Table 18. Performance Evaluation of the MVC Subprojects at the Beginning of the Allowed Makespan

\section{Step 14: Calculate the current $A W R I$ of each subproject}

In order for the division of projects into subprojects to be consistent, the set of subprojects has to provide the same benefits as its source project. This constraint is more easily accomplished by evolving the WRI into an adjusted weighted relevance index, or $A W R I$. In formal terms, the $A W R I$ of a subproject $S P_{\alpha}$ of a project $P$ is 
given by

$$
A W R I\left(S P_{\alpha}\right)=\frac{W R I\left(S P_{\alpha}\right)}{\sum_{\mathrm{i}=1}^{\#(\mathrm{P})} S P_{\mathrm{i}}} \times W R I(P)
$$

where $\#(P)$ is the number of subprojects in $P$.

The rightmost column of Table 18 (shaded) introduces the $A W R I$ of each of the $M V C^{\prime}$ 's subprojects. For instance, according to Table 18, the $\operatorname{WRI}\left(M V C_{1}\right)$ is $12.9 \%$. Moreover, the sum of the WRI of all the $M V C$ subprojects is $143.5 \%$. Also, according to Table 10, the current $W R I(M V C)$ is $46.4 \%$. Therefore, the current $A W R I\left(M V C_{1}\right)$ is $4.2 \%=\frac{12.9 \%}{143.5 \%} \times 46.4 \%$.

\section{Step 15: Evaluate the future performance of each subproject}

Table 19 uses the Extreme, High, Moderate, Small and Insignificant scale of values to introduce the performance evaluation of the $M V C$ subprojects at the end of the allowed makespan. This information is presented with an unshaded background.

Table 19. Performance Evaluation of the MVC Subprojects at the End of the Allowed Makespan

\begin{tabular}{|c|c|c|c|c|c|}
\hline \multirow{2}{*}{ Sub-project } & \multicolumn{3}{|c|}{ Criterion } & \multirow{2}{*}{$\begin{array}{c}\text { Current } \\
\text { WRI } \\
(\%)\end{array}$} & \multirow{2}{*}{$\begin{array}{c}\text { Current } \\
\text { AWRI } \\
(\%)\end{array}$} \\
\hline & PS & MC & EI & & \\
\hline$M V C_{1}$ & Small & Small & Insig. & 6.6 & 1.6 \\
\hline$M V C_{2}$ & Small & Small & Insig. & 6.6 & 1.6 \\
\hline$M V C_{3}$ & Small & Small & Insig. & 6.6 & 1.6 \\
\hline$M V C_{4}$ & Small & Small & Insig. & 6.6 & 1.6 \\
\hline$M V C_{5}$ & Moderate & Small & High & 12.6 & 3.1 \\
\hline$M V C_{6}$ & Moderate & Small & High & 12.6 & 3.1 \\
\hline & & & Total & 51.6 & 12.6 \\
\hline
\end{tabular}

\section{Step 16: Compute the future AWRI of each subproject}

Table 19 also presents the WRI and $A W R I$ of subprojects comprising the $M V C$ project. This information is presented with a shaded background. The figures presented in Table 19 takes into account that the deliverables of those subprojects are made available at the end of the allowed portfolio makespan.

\section{Step 17: Relating subprojects present and future performance}

Table 20 presents the effect of the passage of time on the AWRI of the subprojects comprising the MVC project. Observe that the figures presented in period one and period $W O$ correspond respectively to the current and future AWRI of those subprojects. See Tables 18 and 19 in this respect.

Table 20. The Effect of the Passage of Time on the AWRI of the MVC Subprojects

\begin{tabular}{|c|c|c|c|c|c|c|c|c|c|c|}
\hline \multirow{2}{*}{ Project } & \multicolumn{10}{|c|}{ Period } \\
\cline { 2 - 11 } & $\mathbf{1}$ & $\mathbf{2}$ & $\mathbf{3}$ & $\mathbf{4}$ & $\ldots$ & $\boldsymbol{M k S p - 1}$ & $\boldsymbol{M k S p}$ & $\boldsymbol{M k S p + 1}$ & $\ldots$ & $\boldsymbol{W} \boldsymbol{.}$ \\
\hline \hline$M V C_{1}$ & $4.2 \%$ & $4.0 \%$ & $3.9 \%$ & $3.7 \%$ & $\ldots$ & $1.8 \%$ & $1.6 \%$ & $1.6 \%$ & $\ldots$ & $1.6 \%$ \\
\hline$M V C_{2}$ & $3.8 \%$ & $3.7 \%$ & $3.6 \%$ & $3.5 \%$ & $\ldots$ & $1.7 \%$ & $1.6 \%$ & $1.6 \%$ & $\ldots$ & $1.6 \%$ \\
\hline$M V C_{3}$ & $4.2 \%$ & $4.0 \%$ & $3.9 \%$ & $3.7 \%$ & $\ldots$ & $1.8 \%$ & $1.6 \%$ & $1.6 \%$ & $\ldots$ & $1.6 \%$ \\
\hline$M V C_{4}$ & $4.2 \%$ & $4.0 \%$ & $3.9 \%$ & $3.7 \%$ & $\ldots$ & $1.8 \%$ & $1.6 \%$ & $1.6 \%$ & $\ldots$ & $1.6 \%$ \\
\hline$M V C_{5}$ & $15.0 \%$ & $14.3 \%$ & $13.6 \%$ & $12.9 \%$ & $\ldots$ & $3.8 \%$ & $3.1 \%$ & $3.1 \%$ & $\ldots$ & $3.1 \%$ \\
\hline$M V C_{6}$ & $15.0 \%$ & $14.3 \%$ & $13.6 \%$ & $12.9 \%$ & $\ldots$ & $3.8 \%$ & $3.1 \%$ & $3.1 \%$ & $\ldots$ & $3.1 \%$ \\
\hline
\end{tabular}

It should be noted that the AWRI of the subprojects exhibit a behaviour that is consistent with the behaviour of the WRI of their source project, i.e. the $M V C$ project. It decreases until the end of the allowed 
makespan and from that point on retains a residual value that lasts until the end of the window of opportunity. Table 21 shows the effect of the passage of time on some of the remaining subprojects in Sobek's portfolio of e-gov projects.

Table 21. The Effect of the Passage of Time on the AWRI of the WPS, TFM and TLC Subprojects

\begin{tabular}{|c|c|c|c|c|c|c|c|c|c|c|}
\hline \multirow{2}{*}{ Project } & \multicolumn{10}{|c|}{ Period } \\
\cline { 2 - 11 } & $\mathbf{1}$ & $\mathbf{2}$ & $\mathbf{3}$ & $\mathbf{4}$ & $\ldots$ & $\mathbf{M k S p - 1}$ & MkSp & MkSp+1 & $\ldots$ & W0 \\
\hline \hline$W P S_{1}$ & $1.8 \%$ & $1.8 \%$ & $1.8 \%$ & $1.8 \%$ & $\ldots$ & $1.1 \%$ & $1.1 \%$ & $1.1 \%$ & $\ldots$ & $1.1 \%$ \\
\hline$W P S_{2}$ & $1.7 \%$ & $1.7 \%$ & $1.7 \%$ & $1.7 \%$ & $\ldots$ & $1.1 \%$ & $1.1 \%$ & $1.1 \%$ & $\ldots$ & $1.1 \%$ \\
\hline$\vdots$ & $\vdots$ & $\vdots$ & $\vdots$ & $\vdots$ & $\vdots$ & $\vdots$ & $\vdots$ & $\vdots$ & $\vdots$ & $\vdots$ \\
\hline$W P S_{7}$ & $2.9 \%$ & $2.8 \%$ & $2.7 \%$ & $2.6 \%$ & $\ldots$ & $1.4 \%$ & $1.3 \%$ & $1.3 \%$ & $\ldots$ & $1.3 \%$ \\
\hline \hline$T F M_{1}$ & $8.2 \%$ & $7.8 \%$ & $7.5 \%$ & $7.2 \%$ & $\ldots$ & $3.0 \%$ & $2.6 \%$ & $2.6 \%$ & $\ldots$ & $2.6 \%$ \\
\hline$T F M_{2}$ & $8.3 \%$ & $7.9 \%$ & $7.6 \%$ & $7.3 \%$ & $\ldots$ & $3.0 \%$ & $2.7 \%$ & $2.7 \%$ & $\ldots$ & $2.7 \%$ \\
\hline$\vdots$ & $\vdots$ & $\vdots$ & $\vdots$ & $\vdots$ & $\vdots$ & $\vdots$ & $\vdots$ & $\vdots$ & $\vdots$ & $\vdots$ \\
\hline$T F M_{8}$ & $14.4 \%$ & $13.8 \%$ & $13.3 \%$ & $12.7 \%$ & $\ldots$ & $5.4 \%$ & $4.9 \%$ & $4.9 \%$ & $\ldots$ & $4.9 \%$ \\
\hline \hline$T L C_{1}$ & $1.6 \%$ & $1.6 \%$ & $1.5 \%$ & $1.5 \%$ & $\ldots$ & $1.1 \%$ & $1.1 \%$ & $1.1 \%$ & $\ldots$ & $1.1 \%$ \\
\hline$T L C_{2}$ & $4.6 \%$ & $4.4 \%$ & $4.2 \%$ & $4.0 \%$ & $\ldots$ & $1.4 \%$ & $1.2 \%$ & $1.2 \%$ & $\ldots$ & $1.2 \%$ \\
\hline$\vdots$ & $\vdots$ & $\vdots$ & $\vdots$ & $\vdots$ & $\vdots$ & $\vdots$ & $\vdots$ & $\vdots$ & $\vdots$ & $\vdots$ \\
\hline$T L C_{5}$ & $4.0 \%$ & $3.9 \%$ & $3.8 \%$ & $3.7 \%$ & $\ldots$ & $2.0 \%$ & $1.9 \%$ & $1.9 \%$ & $\ldots$ & $1.9 \%$ \\
\hline
\end{tabular}

\section{Step 18: Capture the dependency relations}

Fig. 1 shows the dependency relations that are required to hold true among the subprojects of the MVC project. Fig. 2-Fig. 4 present the dependency diagram of the WPS, TFM and TLC subprojects respectively.

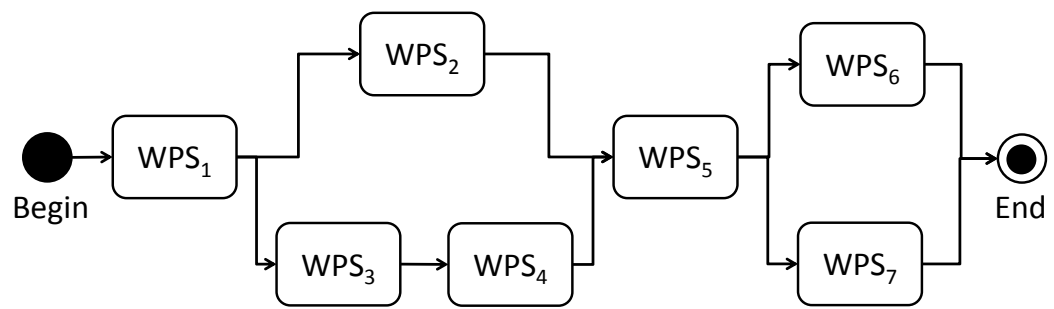

Fig. 2. Dependency diagram of the WPS subprojects.

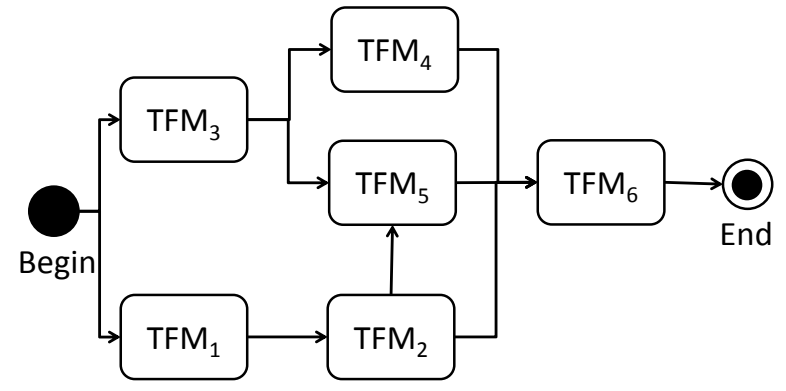

Fig. 3. Dependency diagram of the TFM subprojects.

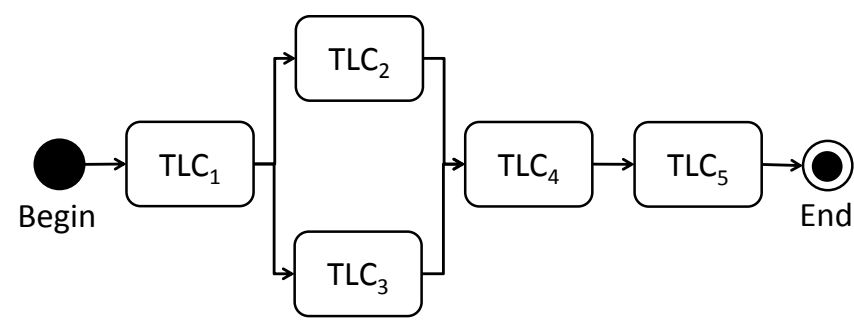

Fig. 4. Dependency diagram of the $T L C$ subprojects. 


\section{Step 19: Estimate the cost of development and returns}

One cannot get something for nothing [58]. Therefore, e-gov projects need capital to be run. Table 5 and Table 6 show respectively the cash flow and $N P V$ of the $M V C$ subprojects. Tables 22 and 23 present some of the cash-flow elements and NPVs of the remaining subprojects in Sobek's portfolio of e-gov projects.

Table 22. Cash Flow of the WPS, TFM and TLC Subprojects

\begin{tabular}{|c|c|c|c|c|c|c|c|c|c|c|}
\hline \multirow{2}{*}{$\begin{array}{l}\text { Sub- } \\
\text { proj. }\end{array}$} & \multirow{2}{*}{$M k S p$} & \multicolumn{9}{|c|}{ Period $(\$ 1.000 \mathrm{~K})$} \\
\hline & & 1 & 2 & 3 & 4 & $\ldots$ & 27 & 28 & 29 & 30 \\
\hline$W P S_{1}$ & 1 & -10 & 0 & 0 & 0 & $\ldots$ & 0 & 0 & 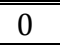 & 0 \\
\hline$W P S_{2}$ & 2 & -50 & -40 & 0 & 0 & $\ldots$ & 0 & 0 & 0 & 0 \\
\hline$\vdots$ & $\vdots$ & $\vdots$ & $\vdots$ & $\vdots$ & $\vdots$ & $\vdots$ & $\vdots$ & $\vdots$ & $\vdots$ & $\vdots$ \\
\hline$W S_{6}$ & 1 & -30 & -20 & 0 & 0 & $\ldots$ & 0 & 0 & 0 & 0 \\
\hline Total & 9 & & & & & & & & & \\
\hline$T F M_{1}$ & 2 & -40 & -20 & 0 & 0 & $\ldots$ & 0 & 0 & 0 & 0 \\
\hline $\mathrm{TFM}_{2}$ & 1 & -65 & 0 & 0 & 0 & $\ldots$ & 0 & 0 & 0 & 0 \\
\hline$\vdots$ & $\vdots$ & $\vdots$ & $\vdots$ & $\vdots$ & $\vdots$ & $\vdots$ & $\vdots$ & $\vdots$ & $\vdots$ & $\vdots$ \\
\hline $\mathrm{TFM}_{8}$ & 1 & -70 & 0 & 0 & 0 & $\ldots$ & 0 & 0 & 0 & 0 \\
\hline Total & 9 & & & & & & & & & \\
\hline $\mathrm{TLC}_{1}$ & 1 & -20 & -5 & 0 & 0 & $\ldots$ & 0 & 0 & 0 & 0 \\
\hline $\mathrm{TLC}_{2}$ & 2 & -60 & -30 & 0 & 0 & $\ldots$ & 0 & 0 & 0 & 0 \\
\hline$\vdots$ & $\vdots$ & $\vdots$ & $\vdots$ & $\vdots$ & $\vdots$ & $\vdots$ & $\vdots$ & $\vdots$ & $\vdots$ & $\vdots$ \\
\hline $\mathrm{TLC}_{5}$ & 1 & -80 & 0 & 0 & 0 & $\ldots$ & 0 & 0 & 0 & 0 \\
\hline Total & 9 & & & & & & & & & \\
\hline
\end{tabular}

Table 23. NPVs of the WPS, TFM and TLC Subprojects According to the Period When Their Development Starts

\begin{tabular}{|c|c|c|c|c|c|c|}
\hline \multirow{2}{*}{$\begin{array}{l}\text { Sub- } \\
\text { proj. }\end{array}$} & \multicolumn{6}{|c|}{ Period $(\$ 1.000 \mathrm{~K})$} \\
\hline & 1 & 2 & 3 & 4 & $\ldots$ & 30 \\
\hline WPS & -10 & -10 & -10 & -10 & $\ldots$ & -8 \\
\hline$W P S_{2}$ & -89 & -88 & -88 & -87 & $\ldots$ & -39 \\
\hline$\vdots$ & $\vdots$ & $\vdots$ & $\vdots$ & $\vdots$ & $\vdots$ & $\vdots$ \\
\hline$W P S_{6}$ & 1,427 & 1,378 & 1,311 & 1,253 & $\ldots$ & -24 \\
\hline TFM & -59 & -59 & -58 & -58 & $\ldots$ & -31 \\
\hline $\mathrm{TFM}_{2}$ & -64 & -64 & -63 & -63 & $\ldots$ & -51 \\
\hline$\vdots$ & $\vdots$ & $\vdots$ & $\vdots$ & $\vdots$ & $\vdots$ & $\vdots$ \\
\hline $\mathrm{TFM}_{8}$ & -69 & -69 & -68 & -68 & $\ldots$ & -55 \\
\hline $\mathrm{TLC}_{1}$ & -25 & -25 & -24 & -24 & $\ldots$ & -16 \\
\hline $\mathrm{TLC}_{2}$ & -89 & -88 & -87 & -86 & $\ldots$ & -47 \\
\hline$\vdots$ & $\vdots$ & $\vdots$ & $\vdots$ & $\vdots$ & $\vdots$ & $\vdots$ \\
\hline $\mathrm{TLC}_{5}$ & -79 & -79 & -78 & -77 & $\ldots$ & -63 \\
\hline
\end{tabular}

\section{Step 20: Identifying the financial constraints}

Considering Sobek current financial and economical scenario, the TCMO has determines that the capital available for investment (CAI) in the portfolio of e-gov projects is $\$ 280 \mathrm{~K}$ and that an interest rate of $0.8 \%$ per period should be used to discount subprojects' cash flow.

\section{Step 21: Identifying the operational constraints}

Unfortunately, it is not always the case that projects run at the taxpayer's expense yield the value that they should. In this respect, consider the project of building a public hospital somewhere in the world. Allow this project to be divided into three large subprojects. The first involves the construction of the hospital building and parking area. The second concerns equipping and furnishing the hospital. Finally, the third regards staffing the hospital with competent professionals.

Note that, if the project makespan is short, any one of these three subprojects may have to be left out. In 
this case, if only the first subproject is completed, then the hospital is built, but it has no staff, no equipment and no furniture.

As a result, no benefits would be appropriated by the general public. On the other hand, if only the second subproject is completed, then furniture and equipment are acquired, but there is no building to house them and no medical staff to utilize the equipment and attend to the public.

In addition, if only the third subproject is completed, then the staff are hired, but there is no hospital building and no equipment and furniture to be used. Either way the final result is the same, i.e. no benefits are appropriated by the general public. This holds true even if any two of these subprojects are completed and the remaining one is not. Therefore, in these circumstances, it is important that if any of the subprojects is run, all the remaining subprojects have to be completed. If this cannot be done, than it is better to run no subprojects at all.

In regard to Sobek, the coming election may alter the city's political landscape considerably. Consequently, the mayor's office cannot guarantee the support of the future mayor with respect to the e-gov projects. Hence, they have decided that if a project starts then all its subprojects have to be completed within the allowed makespan. This way, whatever projects are implemented, they are sure to provide benefits to the general public.

In formal terms the mayor's office has imposed the following restrictions on the possible implementation sequences for the projects in Sobek's portfolio

$$
\left(\exists p_{i} \in \operatorname{Sub}\left(P_{\alpha}\right): p_{i} \text { in } S\right) \Rightarrow\left(\forall p_{j} \in \operatorname{Sub}\left(P_{\alpha}\right): p_{j} \text { in } S\right)
$$

where $S$ is a possible implementation sequence, $P_{\alpha}$ is a project in the portfolio of e-gov projects under consideration, $\operatorname{Sub}\left(P_{\alpha}\right)$ is the set of all subprojects of $P_{\alpha}, p_{i}$ and $p_{j}$ are subprojects of $P$, and in is an operator that returns true if a subproject can be found in a implementation sequence and false otherwise.

The use of first-order logic expressions to constrain implementation sequences in a less elegant and concise way is presented in [59]. A less powerful but easy to understand graphic convention is used in [16] to reach a similar goal. An introduction to first order logic is presented in [60].

\section{Step 22: Generate implementation sequences}

Generate all possible implementation sequences for the subprojects in the e-gov portfolio that comply with

- the restriction imposed on project completion by the mayor's office,

- the portfolio window of opportunity,

- the allowed makespan and

- the available capital for investment.

Table 24 shows some of the possible implementation sequences for the subprojects in the e-gov portfolio.

\section{Step 23: Calculate the performance parameters of the implementation sequences}

It should be noted that Table XXIV also shows the MkSp, AWRI, CI and ROI (return on investment) of each implementation sequence. The return on investment of an implementation sequence $S$ is given by $R O I(S)=\frac{N P V(S)}{C I(S)}$.

\section{Step 24: Identify the best implementation sequence}

There are two sequences listed in Table 24 that bear the same highest AWRI among all possible implementation sequences. These sequences generate the maximum possible benefits considering the restrictions imposed by the political, financial, and social environment in Sobek. In principle, any of these sequences could be used to implement the project in Sobek's portfolio. However, A tie-breaking criterion is 
presented in the next step, which helps to select the best sequence among those that present the same highest AWRI.

Table 24. Some of the Possible Implementation Sequences for the Subprojects in Sobek's Portfolio of E-Gov Projects

\begin{tabular}{|c|c|c|c|c|c|}
\hline$\#$ & Subproject Implementation Sequences & MkSp & $\begin{array}{c}A W R I \\
(\%)\end{array}$ & $\begin{array}{c}C I \\
(\$ 1 \mathrm{~K})\end{array}$ & $\begin{array}{l}\text { ROI } \\
(\%)\end{array}$ \\
\hline 1 & $\begin{array}{l}\mathrm{MVC}_{1} \rightarrow \mathrm{MVC}_{2} \rightarrow \mathrm{MVC}_{4} \rightarrow \mathrm{MVC}_{6} \rightarrow \mathrm{MVC}_{3} \rightarrow \mathrm{MVC}_{5} \rightarrow \\
\mathrm{TFM}_{1} \rightarrow \mathrm{TFM}_{2} \rightarrow \mathrm{TFM}_{3} \rightarrow \mathrm{TFM}_{5} \rightarrow \mathrm{TFM}_{4} \rightarrow \mathrm{TFM}_{6}\end{array}$ & 18 & $70,7 \%$ & 218 & $954 \%$ \\
\hline 2 & $\begin{array}{l}\mathrm{MVC}_{1} \rightarrow \mathrm{MVC}_{4} \rightarrow \mathrm{MVC}_{2} \rightarrow \mathrm{MVC}_{6} \rightarrow \mathrm{MVC}_{3} \rightarrow \mathrm{MVC}_{5} \rightarrow \\
\mathrm{TFM}_{1} \rightarrow \mathrm{TFM}_{2} \rightarrow \mathrm{TFM}_{3} \rightarrow \mathrm{TFM}_{5} \rightarrow \mathrm{TFM}_{4} \rightarrow \mathrm{TFM}_{6}\end{array}$ & 18 & $70,7 \%$ & 219 & $949 \%$ \\
\hline 3 & $\begin{array}{l}\mathrm{MVC}_{1} \rightarrow \mathrm{MVC}_{2} \rightarrow \mathrm{MVC}_{4} \rightarrow \mathrm{MVC}_{6} \rightarrow \mathrm{MVC}_{3} \rightarrow \mathrm{MVC}_{5} \rightarrow \\
\mathrm{TFM}_{3} \rightarrow \mathrm{TFM}_{1} \rightarrow \mathrm{TFM}_{2} \rightarrow \mathrm{TFM}_{4} \rightarrow \mathrm{TFM}_{5} \rightarrow \mathrm{TFM}_{6}\end{array}$ & 18 & $69,9 \%$ & 219 & $949 \%$ \\
\hline 4 & $\begin{array}{l}\mathrm{TFM}_{3} \rightarrow \mathrm{MVC}_{1} \rightarrow \mathrm{MVC}_{4} \rightarrow \mathrm{MVC}_{2} \rightarrow \mathrm{MVC}_{6} \rightarrow \mathrm{MVC}_{3} \rightarrow \\
\mathrm{MVC}_{5} \rightarrow \mathrm{TFM}_{1} \rightarrow \mathrm{TFM}_{4} \rightarrow \mathrm{TFM}_{2} \rightarrow \mathrm{TFM}_{5} \rightarrow \mathrm{TFM}_{6}\end{array}$ & 18 & $67,9 \%$ & 252 & $722 \%$ \\
\hline 5 & $\begin{array}{l}\mathrm{TFM}_{3} \rightarrow \mathrm{TFM}_{4} \rightarrow \mathrm{TFM}_{1} \rightarrow \mathrm{TFM}_{2} \rightarrow \mathrm{MVC}_{1} \rightarrow \mathrm{TFM}_{5} \rightarrow \\
\mathrm{MVC}_{3} \rightarrow \mathrm{TFM}_{6} \rightarrow \mathrm{MVC}_{4} \rightarrow \mathrm{MVC}_{2} \rightarrow \mathrm{MVC}_{5} \rightarrow \mathrm{MVC}_{6}\end{array}$ & 18 & $65,0 \%$ & 102 & $647 \%$ \\
\hline 6 & $\begin{array}{l}\mathrm{TFM}_{3} \rightarrow \mathrm{TFM}_{4} \rightarrow \mathrm{MVC}_{1} \rightarrow \mathrm{MVC}_{3} \rightarrow \mathrm{TFM}_{1} \rightarrow \mathrm{TFM}_{2} \rightarrow \\
\mathrm{TFM}_{5} \rightarrow \mathrm{TFM}_{6} \rightarrow \mathrm{MVC}_{4} \rightarrow \mathrm{MVC}_{2} \rightarrow \mathrm{MVC}_{5} \rightarrow \mathrm{MVC}_{6}\end{array}$ & 18 & $64,3 \%$ & 102 & $648 \%$ \\
\hline : & 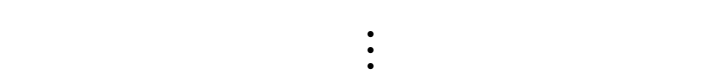 & : & : & : & : \\
\hline
\end{tabular}

It should be noted that none of the subprojects comprising the WPS and TLC projects are part of these implementation sequences. The reasons for this are quite simple. The WPS and TLC subprojects yield on average the lowest AWRI per period among the projects in the portfolio. Therefore they are natural candidates to be left out if the makespan is too short.

Sometimes it might be the case that the number of possible implementation sequences is considerable. In these circumstances one may refer to [61], which presents a branch and bound method that accelerates the identification of the best implementation sequences. In addition, one may also consult [16], which discusses how random samples can be used to identify those sequences within an arbitrary error interval.

\section{Step 25: The tie-breaking criterion}

If the two sequences that bear the highest AWRI and yield different ROIs, the one with the highest ROI would be the logical choice to implement the projects in Sobek's portfolio. Note that this particular sequence would be the one to provide the best possible return on the investment made with taxpayer's money.

Among the sequences that bear the same highest AWRI in Table 24 the first yields a higher ROI. As this sequence provides a better return on taxpayer's money, it should be used to implement the portfolio of e-gov projects.

\section{A Summary of the Method}

Government bodies, organizations and agencies that are willing to run e-gov projects may find it beneficial to pursue

Step 1: E-gov project selection - identify the portfolio $P$ of e-gov projects $P_{1}, P_{2}, \ldots, P_{n}$ that one is willing to run.

Step 2: WO and MkSp elicitation - considering the political, social and economic environment in which the projects $P_{1}, P_{2}, \ldots, P_{n}$ are going to be run, establish the window of opportunity and allowed makespan for $P$.

Step 3: Identify the evaluation criteria - identify the set $E C$ of evaluation criteria $E C_{1}, E C_{2}, \ldots, E C_{k}$ to be 
used to analyse the e-gov projects in $P$. Note that in the scope of this paper these evaluation criteria are expected to remain unchanged during the whole window of opportunity.

Step 4: Prioritize the evaluation criteria - calculate the relevance index $(R I)$ of each evaluation criteria in $E C$.

Step 5: Select the absolute scale - select the absolute scale of values $S V$ that is going to be used to evaluate

the performance of the projects in $P$. Let $S V_{1}, S V_{2}, \ldots, S V_{m}$ be the components of that scale.

Step 6: Work out the RI of each element of the scale - work out the relative importance of each element $\mathrm{SV}_{1}, S V_{2}, \ldots, \mathrm{S} V_{m}$ in $S V$.

Step 7: Evaluate the current performance of the e-gov projects - considering the criteria in $E C$ use the absolute scale of values $S V$ to evaluate the performance of the projects in $P$. When calculating the performance of those projects assume that their deliverables are made available for use at the present time.

Step 8: Calculate the current WRI of each e-gov project - calculate the current weighted relative relevance index of each project $P_{1}, P_{2}, \ldots, P_{n}$ in $P$.

Step 9: Evaluate the future performance of the projects - considering the criteria in $E C$ use the absolute scale of values $S V$ to evaluate the future performance of the projects in P. When calculating the performance of those projects assume that their deliverables are made available for use at the end of the portfolio makespan.

Step 10: Calculate the future WRI of each project - work out the future weighted relative relevance index of each project $P_{1}, P_{2}, \ldots, P_{n}$ in P.

Step 11: Relate the present and future performances - Create a function $F$ that relates the current WRI of each project $P_{1}, P_{2}, \ldots, P_{n}$ in $\mathrm{P}$ with its future $W R I$. Given a project $P_{i}$ and a period $p, F\left(P_{\mathrm{i}}, p\right)$ returns the $W R I$ of $P_{i}$ in period $p$.

Note that this step is optional as its absence will not interfere with the final result of the evaluation process. Nevertheless, it provides an early insight into how the projects' performances vary with the passage of time.

Step 12: Partition the projects - in order to facilitate planning and improve understanding partition the projects $P_{1}, P_{2}, \ldots P_{n}$ into a set of MMFs and AEs subprojects $S P=\left\{S P_{1}, S P_{2}, \ldots, S P_{q}\right\}$.

Step 13: Evaluate the current performance of the subprojects - use the absolute scale of values $S V$ to evaluate the performance of the subprojects in $P$ with respect to the criteria in $E C$. Assume that the deliverables of those subprojects are made available for use at the present time.

Step 14: Calculate the current AWRI of each subproject - calculate the current adjusted weighted relative index ( $A W R I$ ) of each subproject in $S P$.

Step 15: Evaluate the future performance of the subprojects - use the absolute scale of values $S V$ to evaluate the future performance of the subprojects in $P$ with respect to the criteria in $E C$. Assume that the deliverables of those subprojects are made available for use at the end of the portfolio makespan.

Step 16: Compute the future AWRI of each subproject - calculate the future adjusted weighted relative index $(A W R I)$ of each subproject in $S P$.

Step 17: Relating subprojects present and future performance - create a function $G$ that relates the current $A W R I$ of each subproject in $S P$ with its future $A W R I$. Given a subproject $S P_{i}$ and a period $p, G\left(P_{i}, p\right)$ returns the $A W R I$ of $S P_{i}$ in period $p$.

Step 18: Capture the dependency relations - identify the dependency relations that are required to hold true among the subprojects $S P_{1}, S P_{2}, \ldots, S P_{q}$.

Step 19: Estimate the cost of development and returns - establish the cash flow elements of each of the subprojects in $S P$ together with their respective $N P V$ s with respect to the period in which their 
development starts.

Step 20: Identify the financial constraints - determine the capital available for investment and interest rate to guide the development of the projects in $P$.

Step 21: Identify the operational constraints - use first order logical sentences to impose further restrictions on the implementation sequences that are acceptable for implementation.

Step 22: Generate implementation sequences - generate all possible implementation sequences for the subprojects in SP that comply with the constraints identified previously, i.e. dependency relations, available capital investment, allowed $M k S p$, etc.

Step 23: Calculate the performance parameters of the implementation sequences - For each of these subprojects calculate their respective AWRI and ROI.

Step 24: Identify the best implementation sequence(s) - among all possible implementation sequences, select those that provide the highest AWRI.

Step 25: Tie-breaking criteria - if just one implementation sequence bears the highest AWRI, then this sequence is the logical choice to develop the projects in $P$. However, there are circumstances in which two or more implementation sequences have the highest $A W R I$. If this is the case, then the sequence that has the highest $R O I$ is the logical choice to develop the projects in $P$. If several sequences have the same $R O I$, then any of these implementation sequences can be used.

\section{Conclusions}

This work combines, adapts and extends the ideas of Saaty on the evaluation of intangible benefits and the ideas of Denne and Cleland-Huang on the incremental funding of ICT projects. The final result is a method for analyzing investments in information and communication technology that maximizes the amount of intangible benefits yielded by e-gov initiatives.

In many aspects the method presented in this paper is superior to others that have been proposed so far. In addition to taking into account that e-gov initiatives may require the execution of several projects, the method also takes into consideration that those initiatives are frequently divided into a number of subprojects.

Moreover, the method acknowledges that the implementation order of these subprojects may change the value of the e-gov initiative as a whole. Furthermore, it uses the idea that the increase in tax revenue and reduction in running costs yielded by an e-gov subproject may be used to finance the development of other subprojects and system parts. In addition, the depreciation of intangible benefits is considered, enabling us to find the implementation sequence that delivers the maximum benefit with the least capital investment.

Finally, the method acknowledges restrictions placed on the management of portfolios of e-gov initiatives, which are a common concern in the public sector. For example, limitations on available capital and portfolio makespan, and whether or not e-gov projects are permitted to be partly implemented. All of this provides civil servants in decision making position with a more effective tool to analyze e-gov initiatives, especially those that rely solely on taxpayer's money.

Nevertheless, despite all the benefits that the method presented in this paper may provide, decision makers in the public sector may lack the proper academic background to master its use. The AHP, for example, is based on the calculation of eigenvalues and eigenvectors of matrices, which are concepts studied in the mathematical discipline of linear algebra. Note that when the number of possible implementation sequences is considerable, decision makers may have to use branch and bound or random samples to identify acceptable approximate solutions to the best possible implementation sequence. While the former stem from graph theory, the latter requires a reasonable knowledge of statistics.

Moreover, imposing restriction on the composition of possible implementation sequences may require 
the use of first order logic expressions. In addition, the financial aspects of the method may require some knowledge of finance that decision makers may find difficult to master.

However, automation may provide a strong answer to all these difficulties. In this respect, the development of a computer tool that automates the method presented in this paper may go a long way towards facilitating its use. Not only does automation make calculations easy to perform, but it also speeds up the process of identifying the sequence that maximizes the appropriation of intangible benefits.

\section{References}

[1] Rodrik, D. (2011). The Globalization Paradox: Democracy and the Future of the World Economy. W. W. Norton \& Co.

[2] Fisher, C., Lauria, E., \& Smith, S. C. (2011). Introduction to Information Quality. Author House.

[3] Chun, S. A., Shulman, S., Sandoval, R., \& Hovy, E. (2010). Government 2.0: Making connections between citizens, data and government, Information Policy, 15, 1-9.

[4] Howard, M. (2001). E-government across the globe: how will "e" change government? Government finance review, 17(4), 6-9.

[5] Saaty, T. L. (2013). Decision Making for Leaders: The Analytic Hierarchy Process for Decisions in a Complex World (3rd ed.). RWS Publications.

[6] Cleland, H., Czauderna, A., \& Keenan, E. (2013). A persona-based approach for exploring architecturally significant requirements in agile projects. Requirements Engineering Foundation for Software Quality.

[7] Alencar, A. J., ernandes, R. P., FE, A. S., \& Correa, A. L. (2013). Maximizing the appropriation of the intangible benefits yielded by it investments in the public sector. Journal of Software, 8(7), 1537-1549.

[8] Skielse, G. J., \& Perjons, E. (2011). VAMEE: A value aware method for evaluating inclusive e-government initiatives. Lecture Notes in Business Information Processing, 92, 97-111.

[9] Fuente, M. V. D. L., Ros, L., \& Ortiz, A. (2010), Enterprise modelling methodology for forward and reverse supply chain flows integration. Computers in Industry, 61(7), 702-710.

[10] Kinderen, S. D., Gaaloul, K., \& Proper, H. A. E. (2012). Integrating value modelling into ArchiMate. Lecture Notes in Business Information Processing, 103, 125-139.

[11] Raus, M., Liu, J., \& Kipp, A. (2010). Evaluating IT innovations in a business-to-government context: A framework and its applications. Government Information Quarterly, 27(2), 122-133.

[12] Maholic, J. (2013). Business Cases that Mean Business: A practical guide to identifying, calculating and communicating the value of large scale IT projects. CreateSpace Independent Publishing Platform.

[13] Berghout, E., \& Tan, C. W. (2013). Understanding the impact of business cases on IT investment decisions: An analysis of municipal e-government projects. Information and Management, 50(7), 489-506.

[14] Srivastava, S. C. (2011). Is e-government providing the promised returns? A value framework for assessing e-government impact. Transforming Government: People, Process and Policy, 5(2), 107-113.

[15] Osman, I. H., Anouze, A. L., Irani, Z., Ayoubi, B. A., Lee, H., Balc, A., Medeni, T. D., \& Weerakkody, V. (2014). COBRA framework to evaluate e-government services: A citizen-centric perspective. Government Information Quarterly, 31(2), 243-256.

[16] Fernandes, R. P., Alencar, A. J., Assis, E., \& Correa, A. L. (2014). Analysing IT investments in the public sector: A project portfolio approach. Journal of Software, 9(7), 1200-1213.

[17] Kolmogorov, A. N. (1933). Sulla determinazione empirica delle leggi di probabilità. Giornale dell'Istituto Italiano degli Attuari, 4, 83-91.

[18] Kolmogorov, A. N. (1941). Confidence limits for an unknown distribution function. Annals of Mathematical Statistical, 12(4), 461-463.

[19] Schwalbe, K. (2013). Information Technology Project Management (7th ed.). Cengage Learning.

[20] Guclu, A. N., \& Bilgen, S. (2011). Modelling and assessment of the effectiveness of government 
information technologies - value space approach with a public sector case study in turkey. The Electronic Journal of Information Systems in Developing Countries, 45(4), 1-30.

[21] Tsohou, A., Lee, H., Irani, Z., Weerakkody, V., Osman, I. H., Anouze, A. L., \& Medeni, T. (2013). Proposing a reference process model for the citizen-centric evaluation of e-government services. Transforming Government: People, Process and Policy, 7(2), 240-255.

[22] Zhu J. \& Cook, W. D. (2013). Data Envelopment Analysis: Balanced Benchmarking. Create Space Independent Publishing Platform.

[23] Tan, A., Theodorou, P., \& Over, D. V. (2009). Chapter I: Use of information technology investment management to manage state government information technology investments. Strategic Information Technology and Portfolio Management.

[24] Neuroni, A., Rascon, A., Spichiger, A. \& Riedl, R. (2010). Assessing and evaluating value and cost effectiveness of e-government initiatives: Focusing the step of the financial evaluation. Proceedings of the 11th Annual International Digital Government Research Conference on Public Administration Online: Challenges and Opportunities. Puebla (pp. 105-111).

[25] Larrabee, D. T., \& Voss, J. A. (2013). Valuation Techniques Discounted Cash Flow, Earnings Quality, Measures of Value Added, and Real options. John Wiley \& Sons.

[26] Klischewski, R., \& Ukena, S. (2009). A value network analysis of automated access to e-government services. Proceedings of The Internationale Tagung Wirtschaftsinformatik (pp. 25-27).

[27] Cao, L., Mohan, K., Ramesh, B., \& Sarkar, S. (2013). Adapting funding processes for agile IT projects: an empirical investigation. European Journal of Information Systems, 22(2), 191-205.

[28] Freeman, R. J. (2009). Goals measurement and evaluation of e-gov projects. Handbook of Research on Strategies for Local E-government Adoption and Implementation: Comparative Studies.

[29] Peffers, K., \& Santos, B. L. D. (2013). Research opportunities in information technology funding and system justification. European Journal of Information Systems, 22 (2), 131-138.

[30] Palka, W., Yigitel, G., Jurisch, M. C., Wolf, P., \& Krcmar, H. (2013). Basic approaches for the evaluation of it-investments in egovernment: A literature review. Proceedings of the IFIP E-Government Conference (pp. 16-19).

[31] Wittkowski, K., Moeller, S., \& Wirtz, J. (2013). Firms' intentions to use nonownership services. Journal of Service Research, 16(2), 171-185.

[32] Nurnberg, H. (2014). Applying the new accounting for business combinations and intangible assets to partner admissions. Issues in Accounting Education, 29(4), 527-543.

[33] Levi, M., Johnson, J., Knight, J., \& Alessandrini, S. S. J. (2011). Designing Democratic Government: Making Institutions Work. Russell Sage.

[34] Saaty, T. L., \& Vargas, L. G. (2012). Methods, Concepts and Applications of the Analytic Hierarchy Process.

[35] Saaty, T. L., \& Erdener, E. (1979). A new approach to performance measurement the analytic hierarchy process. Design Methods and Theories, 13(2), 62-68.

[36] Bottero, M., Comino, E., \& Riggio, V. (2011). Application of the analytic hierarchy process and the analytic network process for the assessment of different wastewater treatment systems. Environmental Modelling \& Software, 26(10), 1211-1224;

[37] Sipahi, S., \& Timor, M. (2010). The analytic hierarchy process and analytic network process: An overview of applications. Management Decision, 48(5), 775-808.

[38] Subramanian, N., \& Ramanathan, R. (2012). A review of applications of analytic hierarchy process in operations management. International Journal of Production Economics, 138(2), 215-241.

[39] Lay, D. C. (2012). Linear Algebra and Its Applications. Addison-Wesley.

[40] Kerzner, H. (2013). Project Management: A Systems Approach to Planning, Scheduling, and Controlling.

[41] Huang, J. C., \& Denne, M. (2005). Financially informed requirements prioritization. Proceedings of the 27th International Conference on Software Engineering (ICSE) (pp. 710-711). 
[42] Kruchten, P. (2010). Software architecture and agile software development: a clash of two cultures? Proceedings of the 32nd International Conference on Software Engineering (ICSE) (pp. 497-498)..

[43] Kukreja, N., Payyavula, S., Boehm, B., \& Padmanabhuni, S. (2012). Selecting an appropriate framework for value-based requirements prioritization. Proceedings of the 20th International Conference on Requirements Engineering (pp. 303 - 308).

[44] Gentle, M. (2007). IT Success! Towards a New Model for Information Technology. John Wiley \& Sons.

[45] Ranjbar, M. (2012). Multi-mode renewable resource-constrained allocation in PERT networks. Applied Soft Computing, 12, 82-90.

[46] Alencar, A. J., Taveira, G., Schmitz, E. A., Dias, A. F. D. S., \& Correa, A. L. (2011). Maximizing the financial benefits yielded by IT projects while ensuring their strategic fit. Proceedings of the International Conference on Software Engineering and Knowledge Engineering (SEKE) (pp. 288-295).

[47] Yescombe, E. (2014). Principles of project finance. Amsterdam. Elsevier Academic Press.

[48] Andrade, A. \& Joia, L. A. (2012). Organizational structure and ICT strategies in the brazilian judiciary system. Government Information Quarterly, 29(1), S32-S42.

[49] Cohen, J. A. (2011). Intangible Assets: Valuation and Economic Benefit. John Wiley \& Sons.

[50] Junqueira, A., Diniz, E. H., \& Fernandez, M. (2010). Electronic government implementation projects with multiple agencies. Systems Thinking and E-Participation: ICT in the Governance, 18(1), 1-24.

[51] Alencar, A. J., Doria, J. V., Schmitz, E. A., \& Correa, A. L. (2013). Analysing the incremental funding method and its software project scheduling algorithms. International Journal of Information Processing, $7(2), 30-38$.

[52] Manhire, J. (2013). The Essential Einstein. Create Space Independent Publishing Platform.

[53] Kuchner, M. J. (2011). Marketing for Scientists: How to Shine in Tough Times (1st ed.). Island Press.

[54] Saaty, T. L., \& Vargas, L. G. (2006). Decision Making with the Analytic Network Process: Economic, Political, Social and Technological Applications with Benefits, Opportunities, Costs and Risk. Springer.

[55] Franses, P. H. (2014). Expert Adjustments of Model Forecasts: Theory, Practice and Strategies for Improvement. Cambridge University Press.

[56] Hubbard, D. W. (2014). How to Measure Anything: Finding the Value of Intangibles in Business (3rd ed.) Wiley.

[57] Bon, J. V. (2009). IT Financial Management. Van Haren Publishing.

[58] Hill, N., \& Gold, A. (2010). The Think and Grow Rich Success Journal. Tarcher.

[59] Alencar, A. J., Fernandes, M. C., Schmitz, E. A., \& Correa, A. L. (2015). Evaluating e-government initiatives: An approach based upon the appropriation of tangible and intangible benefits. Handbook of Research on Democratic Strategies and Citizen-Centered E-Government Services.

[60] Fitting, M. (2013). First-Order Logic and Automated Theorem Proving. Springer.

[61] Alencar, A. J., Abreu, E. P. D., \& Schmitz, E. A. (2008). Maximizing the business value of software projects: a branch \& bound approach. Proceedings of the 10th ICEIS (pp. 200-206).

Marcelo Carvalho Fernandes is a Ph.D. candidate with the Federal University of Rio de Janeiro (UFRJ), Brazil. He holds a B.Sc. and M.Sc. in computer science from UFRJ. His research interests include software development methodologies and economics of software engineering.

Antonio Juarez Alencar is a researcher with the Federal University of Rio de Janeiro (UFRJ), Brazil. He received his B.Sc. in mathematics and M.Sc. in system engineering and computer science from UFRJ. He holds a D.Phil. in computer science from Oxford University, England. His research interests include economics of software engineering, IT strategy and risk analysis. 
Eber Assis Schmitz is a professor of computer science with the Federal University of Rio de Janeiro (UFRJ). He holds a B.Sc. in electrical engineering from the Federal University of Rio Grande do Sul (UFRGS), an M.Sc. in electrical engineering from the Federal University of Rio de Janeiro and a Ph.D. in computer science and control from the Imperial College of Science, Technology and Medicine, London, England. His research interests include software development modeling tools, business process modeling and stochastic modeling.

Monica Ferreira da Silva is a researcher with the Federal University of Rio de Janeiro (UFRJ), Brazil. She received her B.Sc. in informatics and M.Sc. in system engineering and computer science from UFRJ. She holds a Ph.D. in business administration from the UFRJ's School of Business. Her research interests include the adoption of technology and IT strategy.

Rigel Procópio Fernandes is a research student with the Military Institute of Engineering (IME), Brazil. He holds a B.Sc. in computer science from Estácio de Sá University and a M.Sc. in informatics from the Federal University of Rio de Janeiro (UFRJ). His research interests include defense engineering, military applications of information and communication technology, software development methodologies and economics of software engineering. 